\title{
Aesthetics of Tashteer in the Arabian Poem between the Past and the Present
}

\author{
Najiya Hussein Al-Tuhami \\ Department of Arabic Language and Literature, College of Revelation Knowledge and Human Sciences, International \\ Islamic University, Malaysia \\ tuhaminagwa@gmail.com
}

\begin{abstract}
:
Survival and advancement of nations is attributed to their literatures. This is because literatures enable individuals to transcend the material life and be able to visualize the noble meanings and the world of aesthetics. Indeed, a language is the best level of describing self and others as it does not originate from the ego, but rather from the laws of the universe and existence. Moreover, it is not only a lexicon, but also a combination of words, indications, gestures, spaces, and imagery. It is, hence, possible to realize the significance of poetry as a definition of all the previous elements. Tashteer is a type of poetic art where a poet does not invent a new idea but rather adopts the idea of poetry by another poet. The poet follows the meter and rhyme set by the original poet, and thus is not allowed much space for creating a purpose apart from the original one. Therefore, a poet is confined to the predefined purpose and notion in terms of grammatical, syntactic and semantic aspects. The paper focuses on the study of the art of Tashteer of poet Ali al-Deeb who performed Tashteer on the poet of Abi Firaas (Araaka 'Asaiyya alDam'). The study aims to introduce the art of Tashteer by addressing its practical aspect. The study also uses the descriptive analytical approach to illustrate the strength points of Mushatir (a poet performing Tashteer) and compare his poet with the original one in terms of serving the concept. The study comprises two parts; Part one is for defining the art of Tashteer in the Arabian poetry. Part two includes the analytical study of the poetry under Tashteer. The study concluded several findings including: al-Deeb clearly comprehended the purposes that Abi Firaas had in his poetry. Thus, he was able to have hold of the main notion of the text both linguistically and semantically. He was even able to penetrate into some of the lines and reveal the thoughts.
\end{abstract}

Keywords: $\quad$ Tashteer, Poetry, Abi Firaas, Poet Ali Al-Deeb, The Poetry (Araaka 'Asiyya AlDam i).

Crossref doi https://doi.org/10.51345/.v31i2.202.g171 


\title{
جماليات التشطير في القصيدة العربية بين الماضي والحاضر
}

\author{
د. ن مجيّة حسين التهامي \\ قسم اللغة العربية وآدابها، كلية معارف الوحي والعلوم الإنسانية، الجامعة العالمية الإسلامية، ماليزيا \\ tuhaminagwa@gmail.com
}

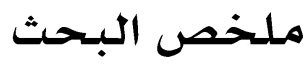

تحيا الأمم وتتفوق بآدابها، لأن الأداب ترقى بالمرء فوق الحياة المادية، وتسمو به إلى المدارك الشريفة، وعالم الجحال، وتعد اللغة أرفع درجات التعبير عن الذات والآخر، فهي قادمة من نواميس الكون والوجود، وهي ليست قاموسا للمفردات فحسب، بل هي جماع المفردات والإشارات والإياءات والفراغات والصور، ومن هنا نستطيع الإمساك بجاهية الشعر بوصفه ذروة الإختزال لكل تلك المقدمات. والتشطير فن من الفنون الشعرية؛ لا يكون فيه المثطرّ شاعراً مبتكراً بل يتبنَّي فكرة الشاعر الأصل، مقيَّدا بوزنه وقافيته، الأمر الذي لا يتيح للمشطر هامشاً واسعاً لابتكار غرض جديد غير الأصل، فيكون بذلك أسيرًا من حيث الغرض ومن حيث الفكرة، ومقيدًا بإحكام البناء اللغوي من الوجهتين النحوية والصرفية، وكذلك الدلالية. يركزهذا البحث على دراسة فن التشطير لدى شاعر ليبي معاصر، وهو الشاعر علي الديب؛ الذي شطرّ رائعة أبي فراس (أراك عصي الدمع)، ويهدف إلى التعريف بفن التشطير، متناولا الجانب التطبيقي من خلال المنهج الوصفي والتحليلي في تبيان مواقع القوة لدى

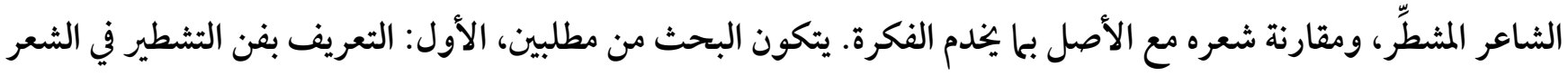
العربي، والثاني: الدراسة التحليلية للقصيدة المشطرة، ويخلص البحث إلى عدة نتائج منها: استيعاب الديب لمرامي أبي فراس في قصيدته التي عايشها، فتمكَّن من امتلاك ناصية النص فكرةً ولغـةً وبيانا، بل تمكَّن من فتح مغاليق بعض الأبيات وما بها من

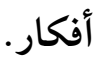

$$
\text { الكلمات المفتاحية: الشعر، التشطير، أبو فراس، الشاعر علي الديب، قصيدة (أراك عصيَّ الدمع). }
$$

Crossref doi) https://doi.org/10.51345/.v31i2.202.g171 


\section{المقلدمة}

يعد الشعر لغة العرب، أجادوا نظمه وتفننو افي بحوره، وقد كانت الجاهلية تقيم الأفراح حين يبرز من أبنائها شاعر مبدع، "فالشعر كان يرفع من شأن قبيلة ويحط من قيمة أخرى. وفي صدر الإسلام، كان وسيلة من وسائل الدفاع عن رسالة الإسلام ضد المشركين. ثم أصبح وسيلة من وسائل الفرق السياسية والفكرية المتنازعة، قصد تبليغ آرائها، والدفاع عن مبادئها، في مواجهة خصومها. وهكذا كان للشعر العربي دور بارز في الحياة الأدبية والفكرية والسياسية، فهو يتطور حسب تطور الشعوب وعلاقاتها بالشعوب الأخرى من فرس وروم وبربر وغيرها"(1) لقد دأب كثير من الشعراء على مر عصور الأدب العربي على إظهار إعجابهم بقصائد معينة، يرونها أقرب إلى نفوسهم، و أعلق بأذهانهم و أذهان محبي الشعر. وهذا الإعجاب ترجمه الكثير في صورة محاكاة لمذه القصيدة أو تلك، مقتبسين منها شيئا مما يتعلق بها، كالوزن العروضي والإيقاع الموسيقي، أو وضوح المعاني والأفكار. ولم يقف الأمر عند حد المحاكاة وإنما تعداه إلى التشطير، وغيره من الجماليات الشعرية الأخرى"(2). وما سيُعرض في هذا البحث؛ هو مثال لفن من فنون الشعر، ألا وهو التشطير، و قد خُصّص للبحث في هذا الفن أنموذجا لقصيدة عربية أصيلة تعد رائعة من روائع الشعر العربي الأصيل؛ هي قصيدة (أراك عصي الدمع لأبي فراس) قام بتشطيرها الشاعر الليبي علي الديب الذي يعد من شعر اء الأدب الحديث. قُسم هذا البحث إلى مطلبين وخاتمة، حيث كرّس المطلب الأول لتعريف التشطير لغة واصطلاحا، أما المطلب الثاني فكان للدراسة والتحليل الفني لتشطير قصيدة (أراك عصي الدمع).

\section{مشكلة البحثث:}

اكتسبت قصيدة أبي فراس الحمداني (أراك عصي الدمع) شهرة واسعة في الأوساط الأدبية، لدرجة جعلتها مضرب الأمثال، ولم تكن هذه الشهرة وليدة تعصب أو هوى، وإنما على العكس تماما، فقد مثلت هذه القصيدة اتجاها في الشعر العربي، ومنهجا في معالجة التجربة التي تقوم عناصرها على القَصص، وتتكيء على التشويق والإثارة، وحضورها بهذه الكثرة في الوجدان العربي إنما يعكس إعجابا بطرائق الفن في هذا النص الشعري 
القديم، الذي أخذ الألباب عن طريق إجادة الحكي وتتابع الأحداث، وهو إعجاب قد تعدّى حدود المعارضة والتضمين والتشطير، إلى محاذاة النهج والطريقة، بها يمكن معه أن يصير نص أبي فراس نصا غائبا، وقد تسرب ذلك النص إلى ذهن شاعرنا (علي الديب) فحاول توظيفه ليقف قارئه على مقارنة الماضي بالحاضر، والتراثي بالمعاصر من خلال قصيدة أبي فراس، نظرا إلى مدى ما حققته من شهرة، ومدى تأثير معانيها الجيدة في نفس الشاعر علي الديب، الذي كان مأخوذا بتلك القصيدة بدافع الإعجاب والاحتذاء، فقد ظهر ذلك واضحا من خلال تشطيره لأبياتها، ومحاولة تحويل القصيدة إلى نص جديد، يتخذ من النص القديم نصا غائبا حاضر افي آن معا. ولذلك فالبحث يطمح إلى تبيان تفاصيل هذه التجربة الشعرية الفذة وشرح مضامينها عبر تأصيل لرؤية عربية نقدية، تنطلق من التراث العربي، لتمد القاريء العربي بها يجفظ له هويته، ويجفظ للقصيدة العربية أصالتها وجودتها في أي مكان؛ لذلك تهدف هذه الورقة البحثية للتعريف بمعنى التشطير لغة واصطلاحا، و إلقاء الضوء على الجانب التطبيقي في تشطير قصيدة الحمداني موضحة خزون اللغة واستلهام التراث، وسعة اطلاع الشاعر المشطرّ (علي الذيب) ومدى إحساسه بالكلمة، ونظرا لضيق المساحة المسموح بها في هذا البحث، فليس بالإمكان التعرض بالتحليل والعرض لكل أبيات التشطير، وإنها وقع الاختيار على نحاذج منها

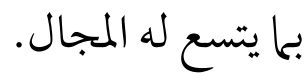

\section{الدراسـات السابقة:}

كتب كثيرون في هذا النوع الأدبي (التشطير)، وذهبو ا إلى تشطير رائية أبي فراس ولكن لم تخضع أعحالهم الأدبية للدر اسة والتحليل،وومنهم على سبيل الإيجاز لا الحصر: لئ

الدراسة الأولى: الكناني الأبياري (سنة 986 هـ) بجلة الرسالة ع 85، 2515 أ الذي شطر قصيدة أبي فراس: ولا خير في دفع الردى بمذلّة إذا لم يكن عز فإن الردى خير ومن يرتضي ردّ الردى بمعرة عما ردها يوماً بسوأته عمرو 
الدراسة الثانية: أحمد بن يجي حميد؛ (1891 1962 1962 ) آخر أئمة اليمن، عالم مجتهد، أديب وشاعر سياسي محنك.

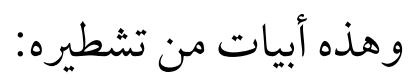

(مهاباً تحامتـك النوائبُُ و والدهـرُ)

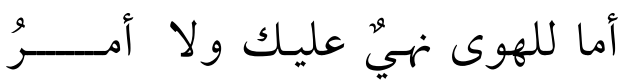

(ولكن لأمـرِ دونسه الأنجـمُ الزهـرُ)

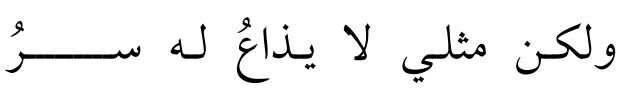

أراك عصي الدمـع شيمتك الصبر

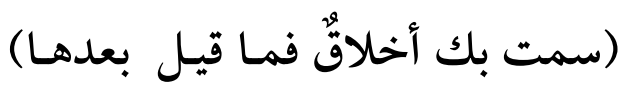

بلى أنا مشتاق وعندي لوعة

(أريد العلى لا أبتغي الدهـر دونهـــا)

الدراسة الثالثة: عبد الله عزت (2 2012 ) الذي قام بتشطير ديو ان الإمام الشافعي في ديو ان أسماه: (فتح العلي في ديو ان الإمام الشافعي)، وهذه أبيات من القصيدة بعد التشطير:

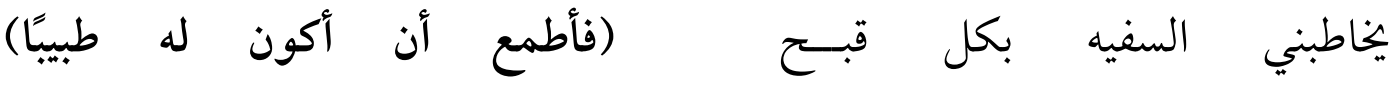

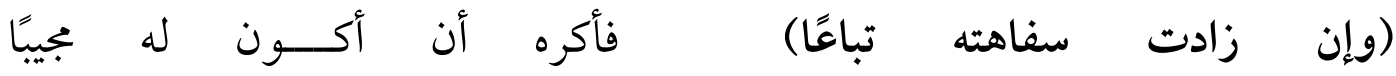

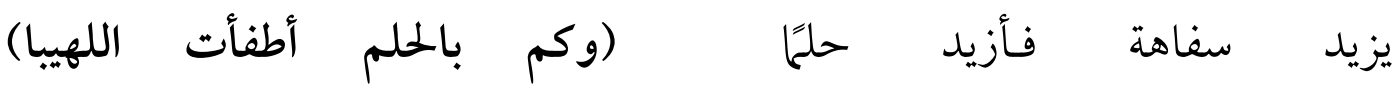

(إن استعذبت منه النار إليَّ)

الدراسة الرابعة: قدس عبد الحميد (2002 002 ) تشطير قصيدة البردة. التشطير هو ما بين القوسين:

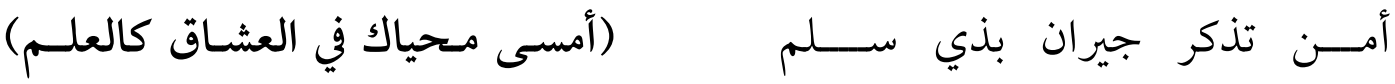

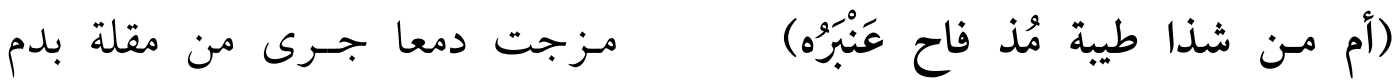

أم هبت الريح من تلقاء كاظمة أم عم نور قُبا الأكوان في الظلمم)

(أم لاح بدرّ بأكناف العقيق دجى) أومض البرق في الظلماء من إضم

نرى من خلال الدراسات السابقة أن التشطير نوع من انواع الأدب قد عرف منذ القدم غير انه لم يمض بدراسات بحثية تقف على هذه التشطير بالو صف والتحليل الفني البلاغي. 


\section{منهجية البحث:}

أخذ البحث منهجين اثنين هما: المنهج الوصفي، والمنهج التحليلي يجري فيه تحليل ألفاظ التشطير. (لا يكون حَديث إلا بعد قديم، و لا يعرف حديث إلا بقديم ، بل قد صار معروفًا تفضيل اشتحال الفن الحديث على طرف من الفن القديم يتألّف المتلقين ويعطفهم).

\section{المطلب الأول : مفهوم التشطير:} التشطير لغة: "الشَطْر في اللغة العربية، أي: النصف، وشَطَرَته: جعلته شطرين أي نصفين، ومنه مشطور

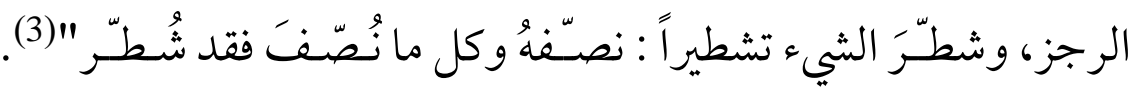
أما التشطير في الاصطلاح فهو: "أن يعمد الشاعر إلى أبيات لغيره فيضمّ إلى كل شطر منها شطراً يزيده عليه عجزاً لصدرِ، وصدراً لعجز"(4). لذلك نستطيع أن نفهم بأن التشطير فن من فنون الشعر يرتبط بشكلٍ وثيق بأوزان الشعر وقوافيه، "وليس الأمر مقصورًا على التقليد؛ فإنّ وحدةً الثقافة التي هي قوام الأمة، تُسَِّبِ إلى أصحابها إطار فن اللغة، كما تسرّّب إليهم إطار اللغة في أصلها"(5).

$$
\text { نص القصيـدة المشطّرة: }
$$

1

2

3

4

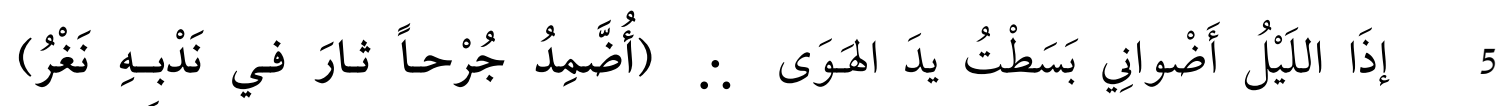

6 


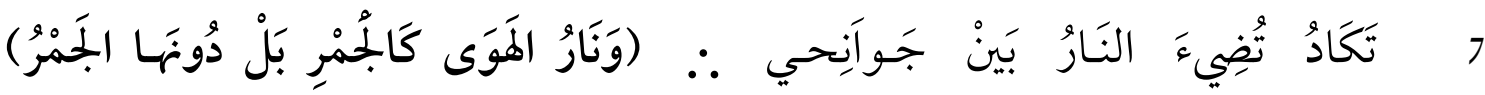
8

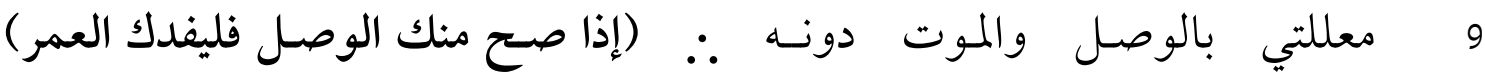
10 11

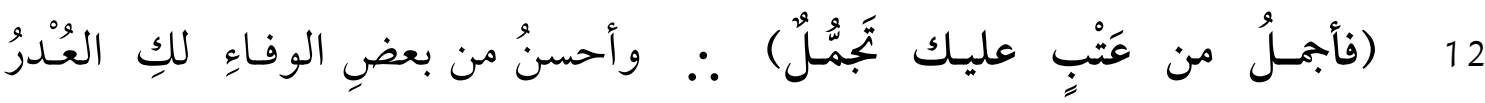
13 14 15

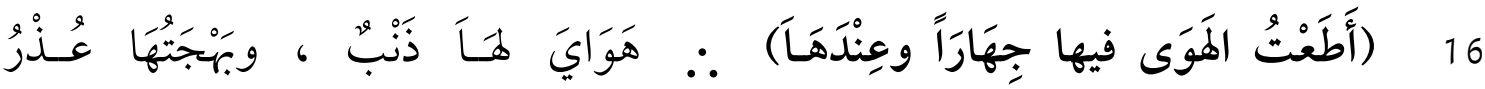
17 18

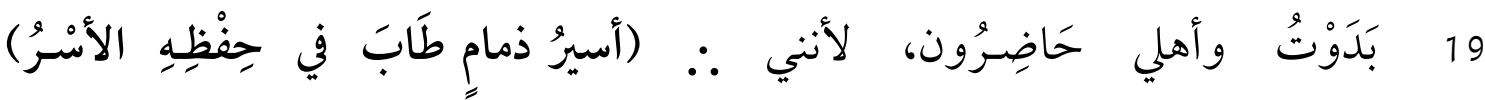
20 21 22

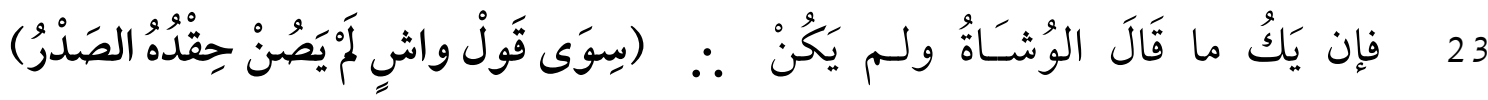
24 25

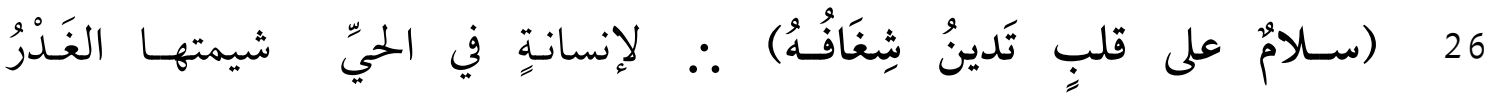




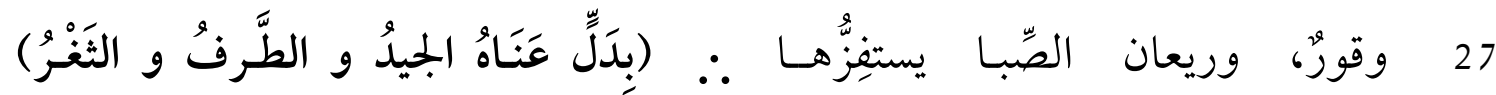

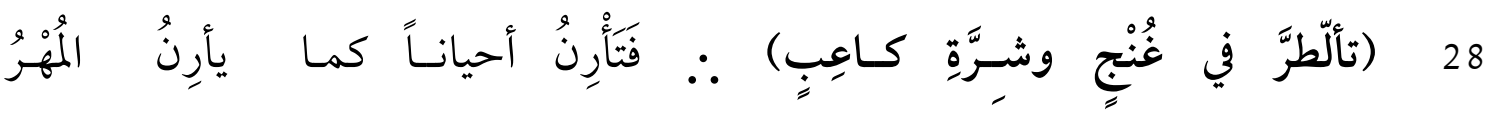

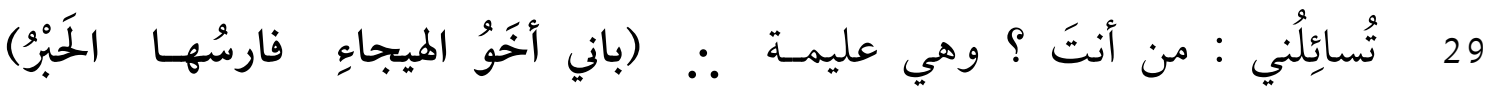

30

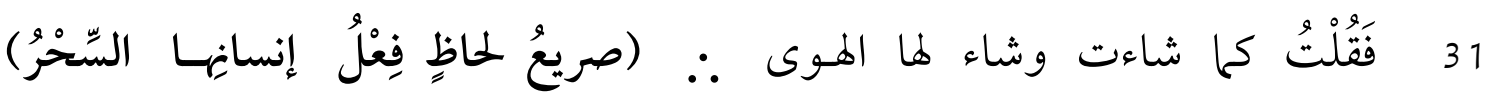

32

33

34

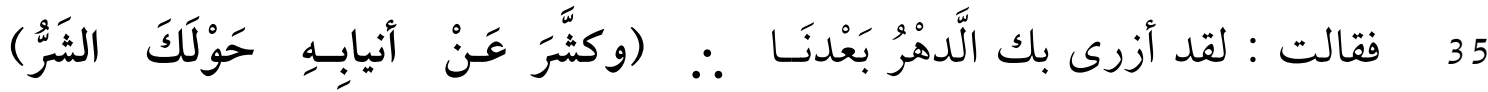

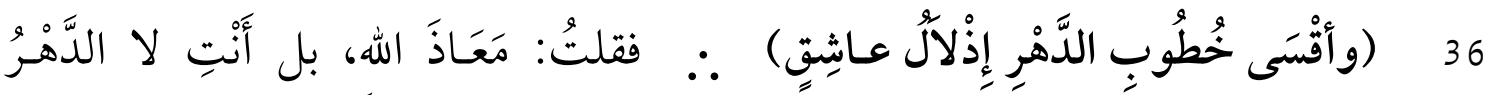

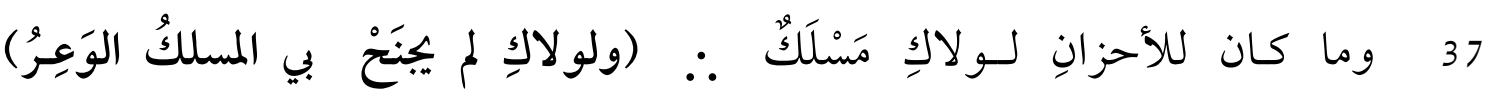

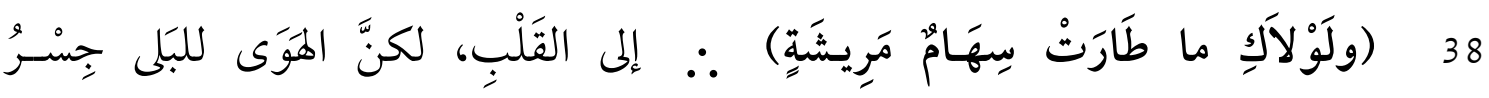

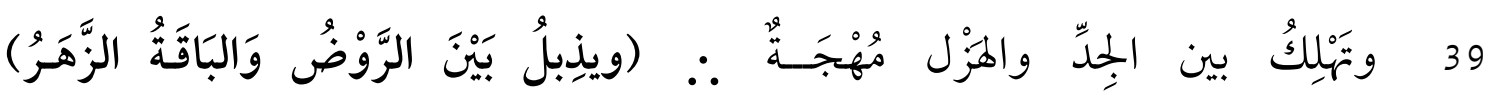

40

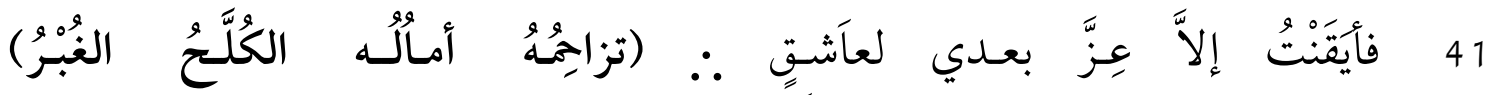

42

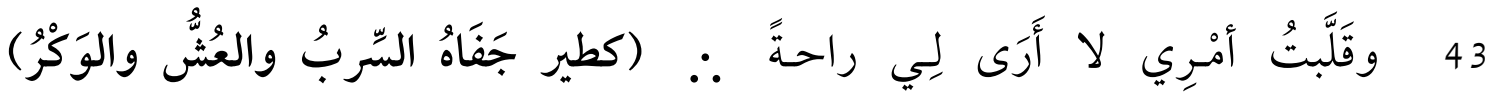

44

45 


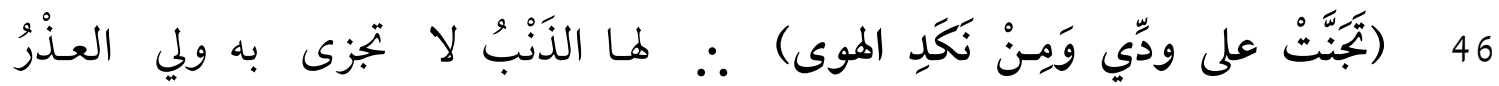

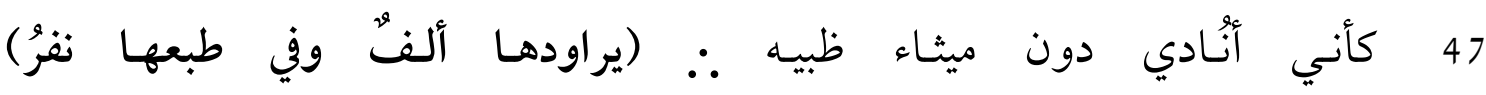

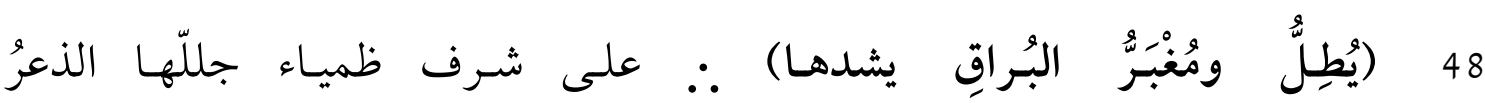

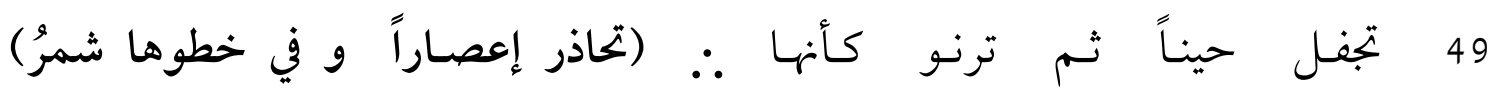
50 51 52 53

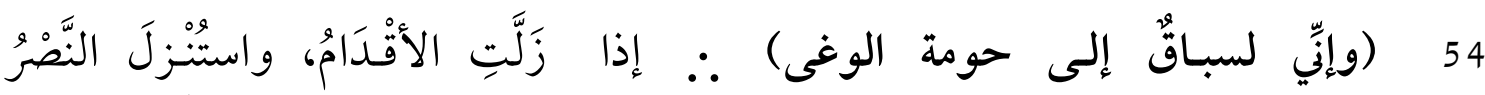

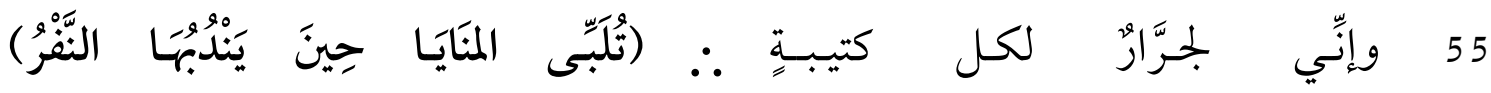

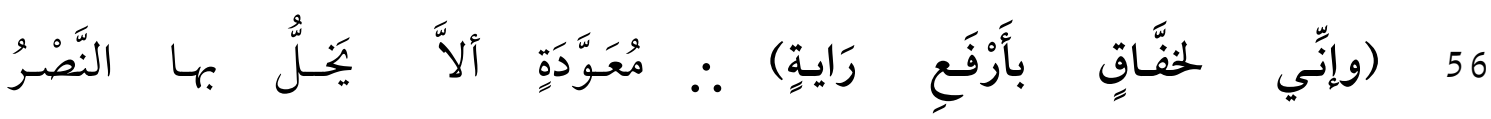
57 وإِتِّي

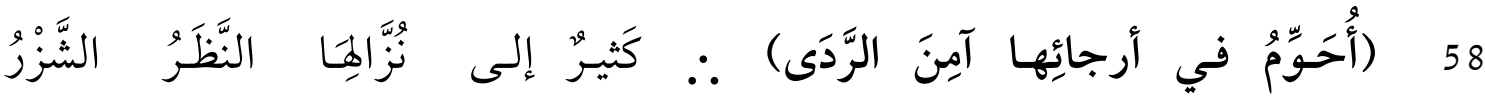

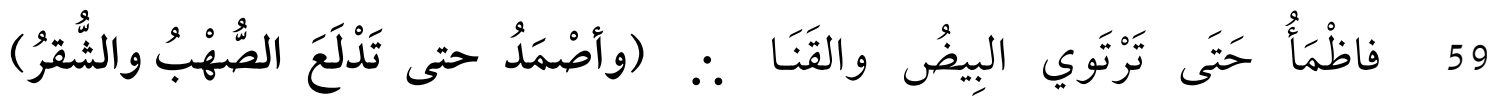

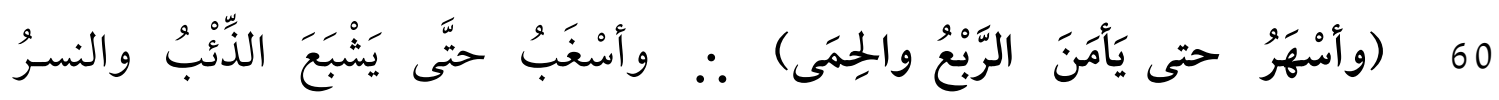
61 62

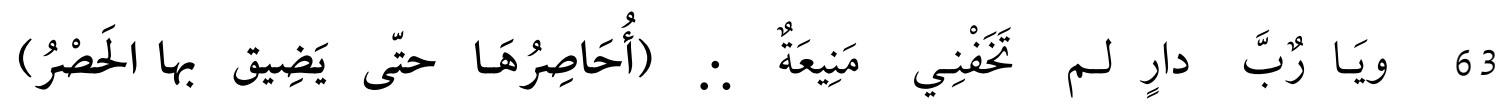

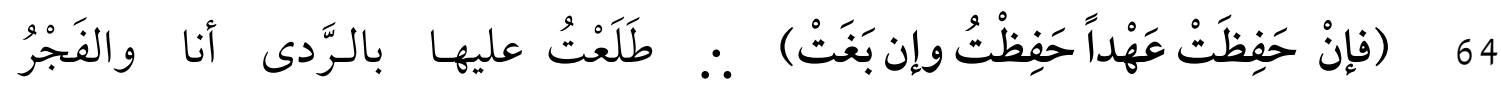

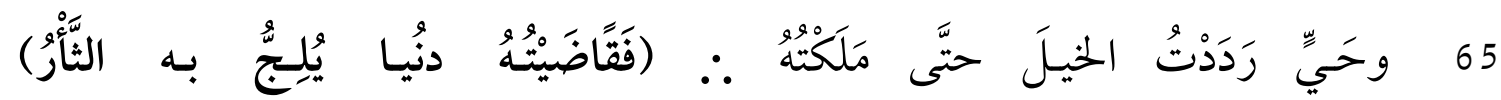




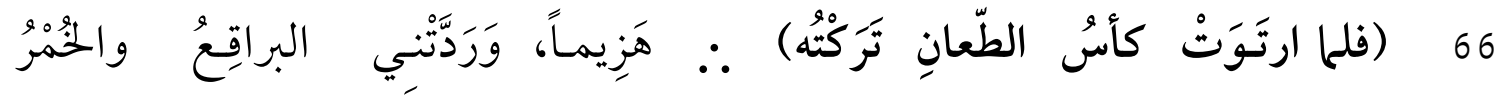

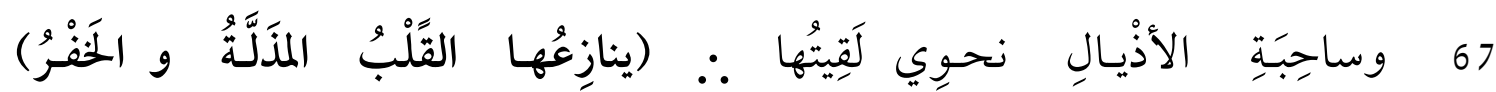

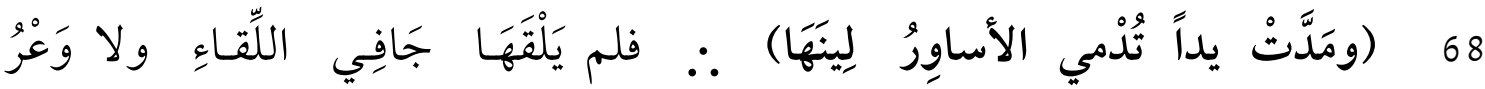

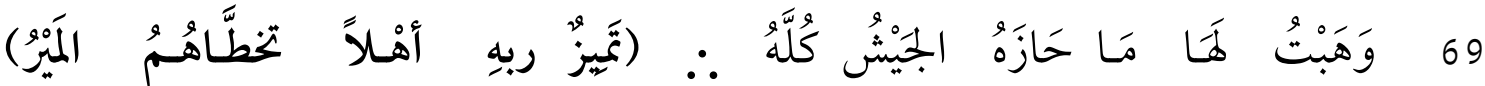

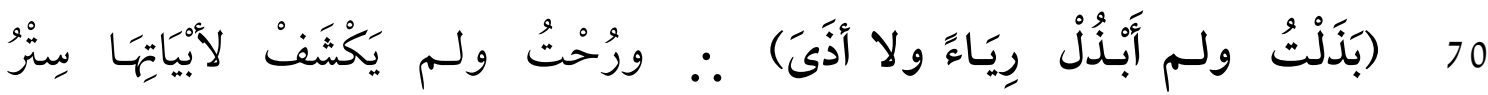

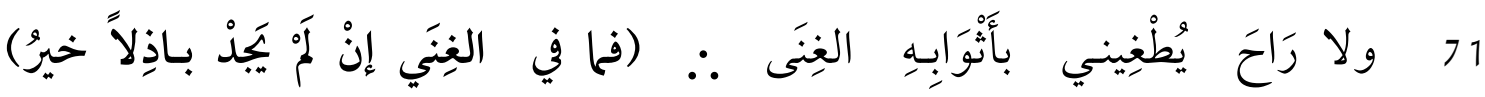
72

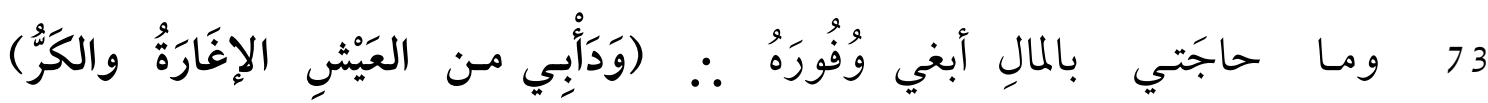
74

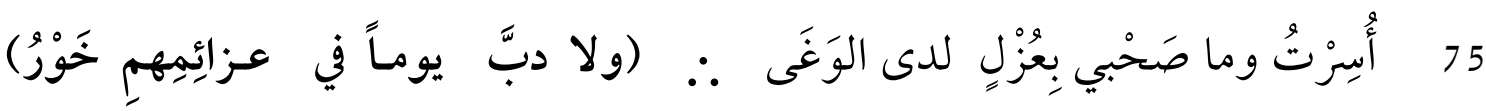

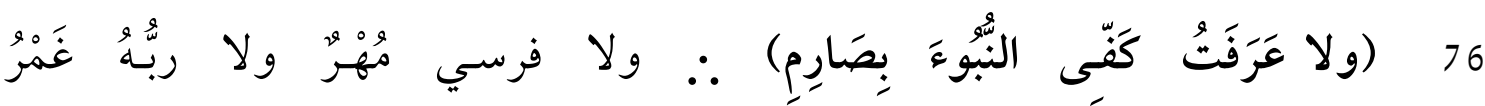

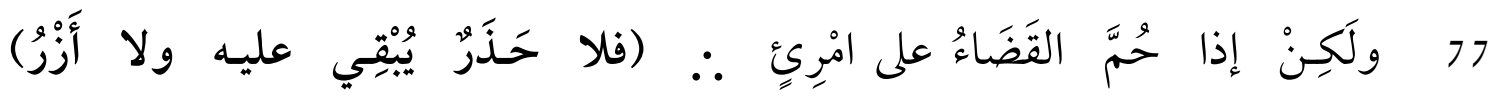

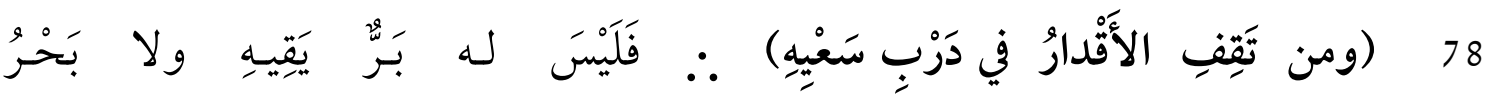

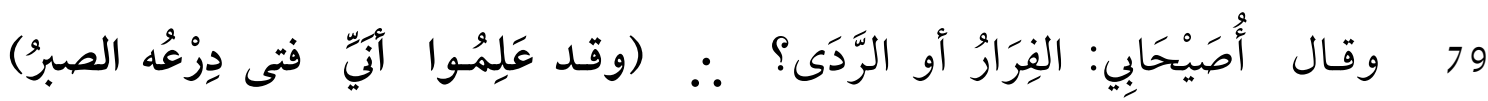
80

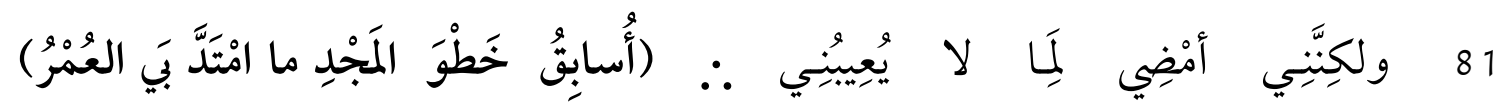
82 83 وهل 82 84 
85 86

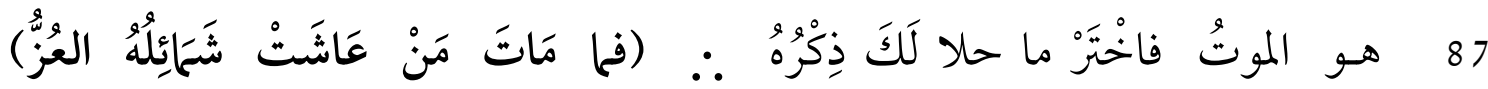
88

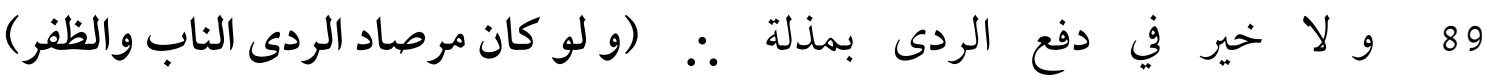

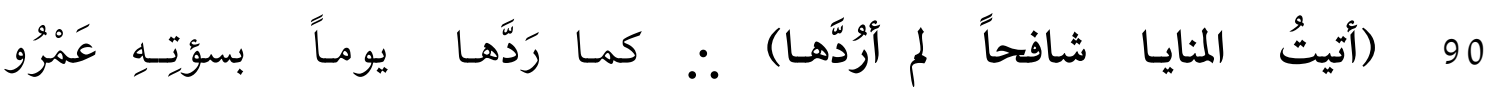
91

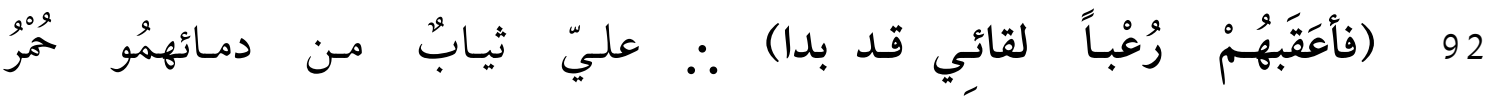

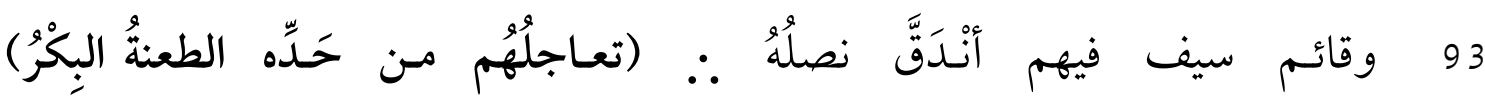
94 (سلِ القومَ يا ابنة العم كيف لقيتهم) . . م وأعقاب رُمْحِ فيهمو قد حُطِّمَ الصَّدرُ

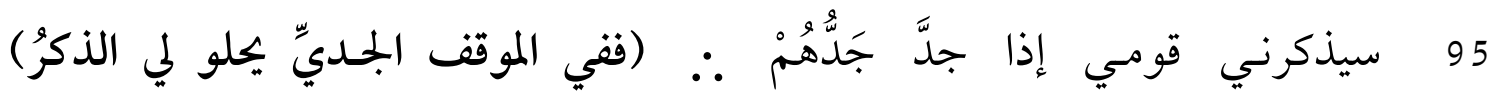
96 (لقـد فقدوني ذات يوم كريهة) ـ. وفي الليلة الظلمـاء يفتقد البـدر

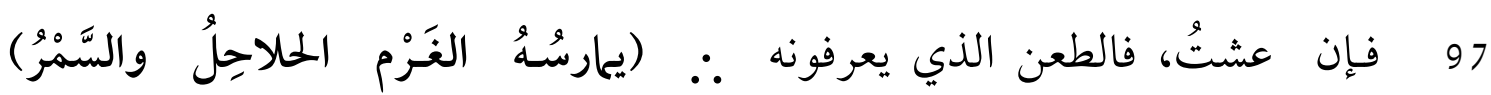

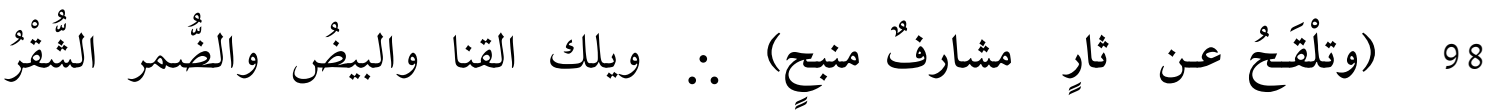

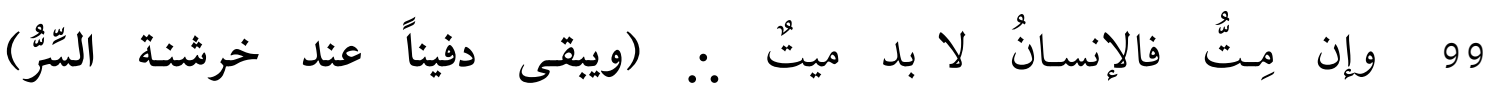

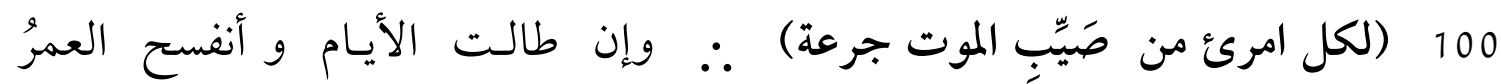

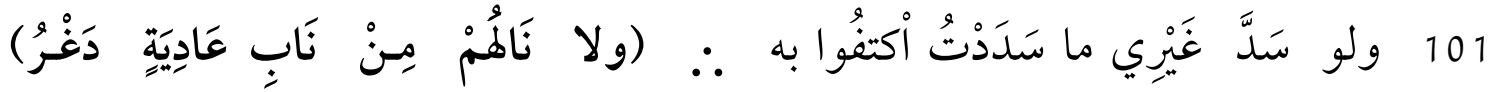
102

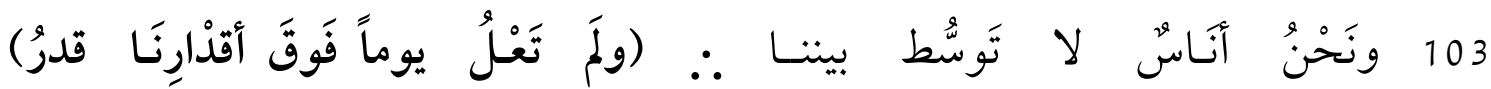

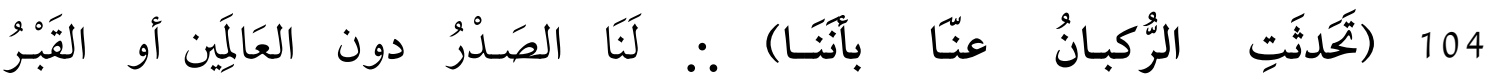


105

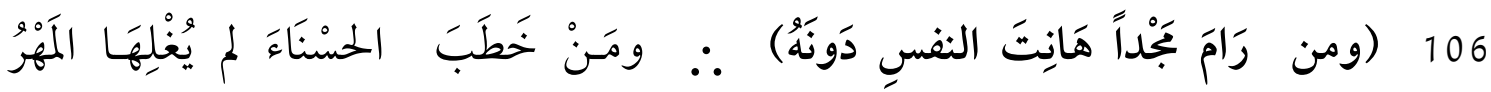

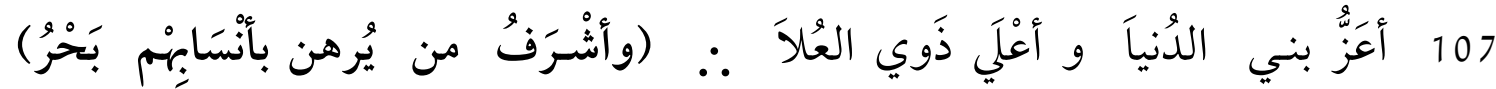

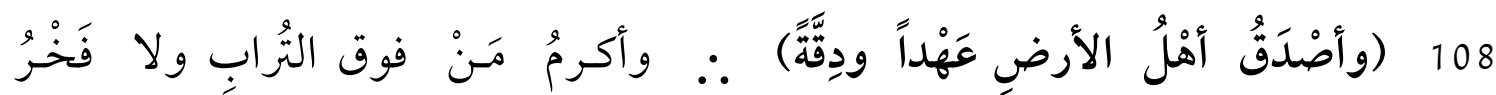

\section{المطلب الثاني: الدراسة والتحليل الفني لتشطير قصيدة (أراك عصي الدمع)}

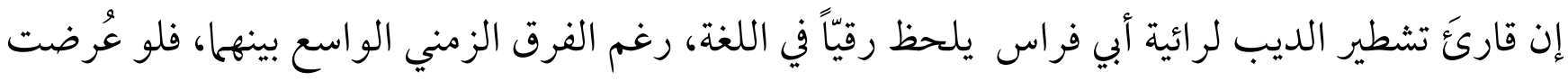

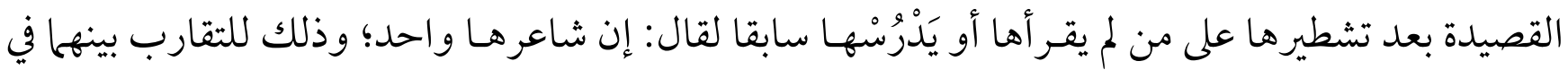
اللغة والخيال و الفكرة ، ورونق الديباجة فيها. أما إذا قيل إن الديب اقتفى أثثر أبي فراس فعندها سيدل هذا بوضوح على تمرسّ الديب في هذا المجال؛ لأنه

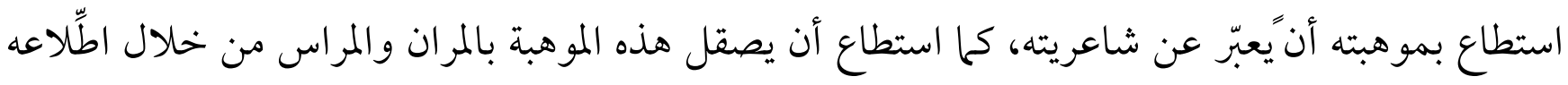
الذاتي على ما وقع تحت يديه من دواوين الشعر، وكتب العربية المتنوعة، التي ما كانت لتصنع منه مُبدعاً لو لا منال

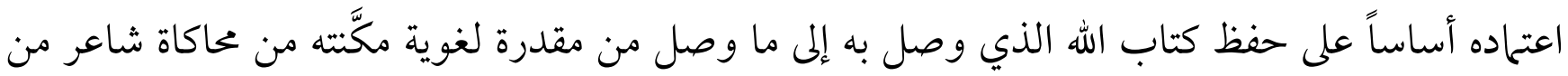
فحول الشعراء، وكذلك النسج على منو ال شعره من خلال هذه التشطيرة التي تمتاز بجزالة اللفظ وفخامة

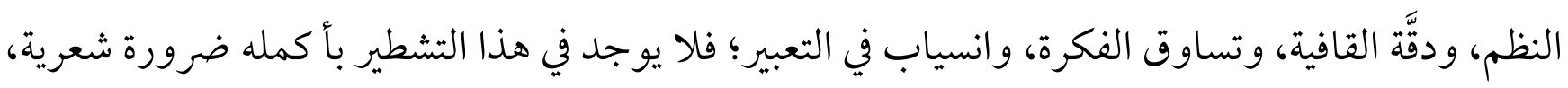
سواء أكانت نحوية، أم صرفية أم عروضية ـ إلاّ ما ندر ـ وهذا دليل على مقدرة الشاعر الديب الفذة التي لئي

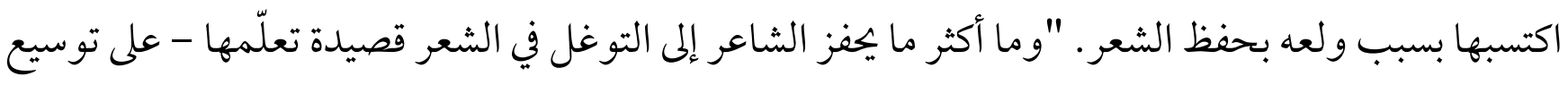
مفهوم التعلم ليشمل طر ائق الثلقي المختلفة كلها، و إذا ما أخفق فإنه يفتش عن وسائل أخرى لفرى ملائمة يؤدي بها رسالة أخرى ممّا يشغله، غير أن الشاعر يظل في نفسه أسير ذلك الفضل "(6). 
وما يميز الديب من خلال دراسة هذا النص، هو تلك الجرأة والشجاعة الأدبية التي دفعته إلى اختيار هذه القصيدة الرصينة المطوَّلة، فهو لم يختر قصيدة لشاعر مغمور، ولم يختر قصيدة لشاعر من معاصريه لاشتراكها في لغة العصر وتشابهها في ظروف المكان، وإنها اختار قصيدة يعدّها النقاد عينًا من عيون الشعر العربي، لشاعرِ عُرفَ بأنه واحد من فحول الشعراء الذين يخلِّهم التاريخ عبر الأزمان والأوطان، فقصيدة الشاعر العباسي (أبي فراس الحمداني)، الشهيرة بمطلعها "أراك عصيَّ الدمع شيمتك الصبر" تُعدّ رائعة من روائع الشعر العباسي بصفة خاصة، ومن فرائد الشعر العربي بصفة عامة، ففي مطلع القصيدة:

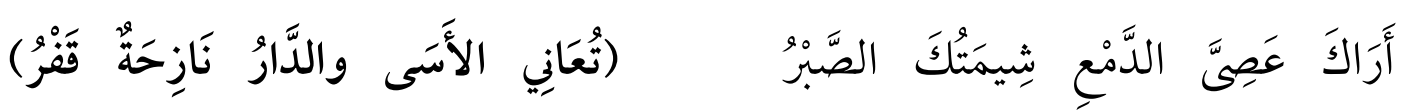

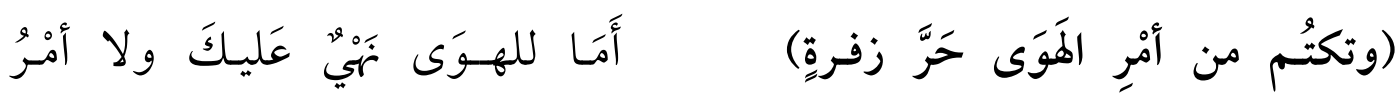
يفسّر الديب في جملة حالية، الحوار الذي دار بين أبي فراس ونفسه، فزاد من القيمة الجمالية للبيت، حيث وسَّع من الصورة التي رسمها أبو فراس عن شخصه، فبينما كان المخاطَبُ عنده عصىَّ الدمع صابراً كما لو لم يكن عليه من الهوى نهيٌّ ولا أمرُ، أصبح المخاطَبُ عند مشطرّها يعاني الأسى والحزنَ وحيداً، وقد أظهرت جملته الحالية " والدارُ نازحةٌ قفرُ " ما يدعو إلى الجزع ويؤكد قدرة الشاعر على الصبر، فهو يعاني الأسى، مع ما لـ توحي به صيغة المضارع "تُعاني" من تجددٍ للمعاناة بشكل مستمر واستحضارها في ذهن المتلقي بشكل دائم. ولم يكتفِ الذيب بالإخبار عن الدار بأنها (نازحة) بل أخبر عنها بخبرِ ثان وهو أنها (قفرُ) ليبين الفراغ الذي يعيشه. ثم ثنى بجملة أخرى بقوله: (وَتَكْتُمَ مِنْ أَمْرِ الهَوَى حَرَّ زَفْرَةٍ)، إذ استعمل صيغة المضارع (تكتم) مع ما توحي به من سيطرة على عقل الشـاعر ويُكمل المعاناة في قوله: "حرَّ زفرة" فالزفرة دليل واضح على القلق والاضطراب والتضجر، فكانت النتيجة الدليلَ الأكبرَعلى صبر المحب بإخفائه لملامح الحزن والأسى وجعل نفسه إنساناً لا ينصاع لأو امر الحب ونو اهيه، وهذا ما يؤيد فكرة أبي فراس الأولى "شيمتك الصبر". 
(وَفِي النَِّْْ حاجات يَضِيقُ بِهَا الصَّدْرُ)

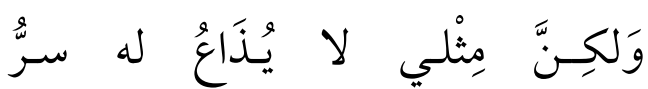

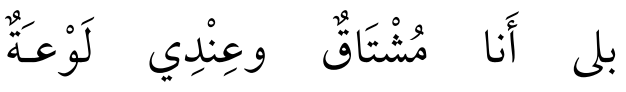

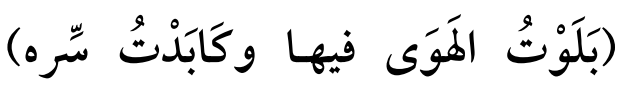

زاد الديب في شطر البيت من اشتياق المحب ولوعته، وصرّح بأن ما لديه مخباً في نفسه، وهي أشياء يضيق بها صدره، من شدة الألم وهول المأساة ولكن مع ذلك يؤثر عدم الإفصاح عنها. إنها الحاجات التي يشير إليها في

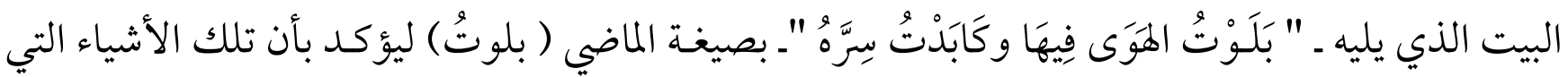
ضاق بها صدره، بلى فيها الهوى، وكابد سرَّه، موضحاً تجربته القاسية على مكابدة الحياة في الحب. أما في البيت الخامس فقد قال أبو فراس:

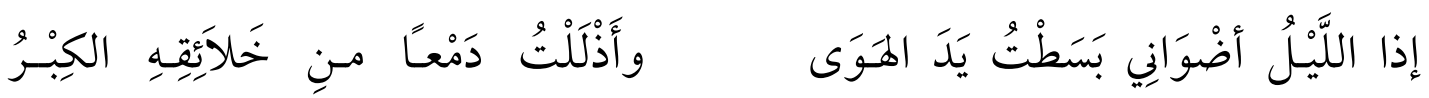
لكن الذيب زاد من مساحة الشطر الأول للبيت ليصبح:

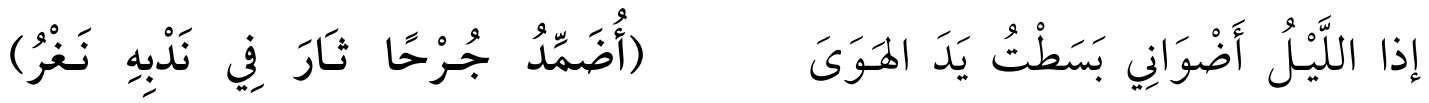

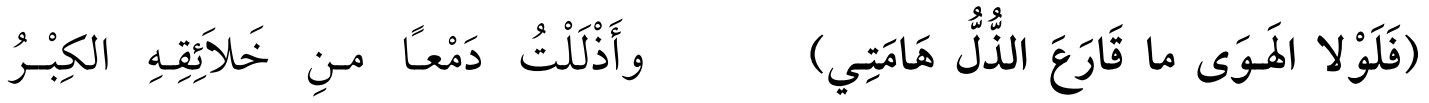
فزاد لنفسه عملاً أتعب قلبَه به، اختار له الزمن المضارع (أُضَمِّدُ) التي توحي باستمرار المعاناة في نفسه، ولم يكتفِ بذكر الجرح وتضميده، وإنها وصف الجرح بـ(النَُُّْ) أي النازف عندما يُثار ندبه، استدراراً لعطف المتلقي وطلباً للتضامن معه، إذ يمكن اعتبار ذلك نوعاً من الشكوى التي نفاها عن نفسه في بداية القصيدة وأثبت بدلاً منها صفة الصبر. فهو لم يترك معاناته ليلاً تمر دون تفاصيل، وإنما شُغل بمداواة جرح غائر في نفسه ناجم عن الهوى الذي سبب له جراحاً متعددة أولها جرح الهجر الذي أُرغم عليه ، وثانيها جرح الأسر الذي وقع فيه، وثالثها جرح الإهمال الذي ما كان يتوقعه من مقربيه. ولعل براعة الذيب اللغوية في صدر البيت بقوله:

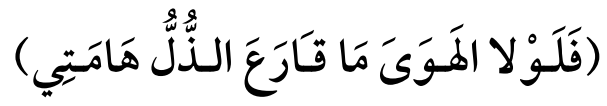


تظهر واضحة جليّة من خلال اختياره للألفاظ، حيث اختار كلمة (قارع) ليظهر بها شدة الأثر في نفسه وكلمة (الذل) التي ترمز للهزيمة والانتكاس، وكلمة (هامتي) التي هي رمز اعتزاز الإنسان بذاته، فالأسر محكوم به عليه، واحتمال وقوعه فيه أمر متوقع لاعتباره فرداً من أفراد الجيش، أما ذل الهوى فلا يستطيع له دفعاً، وهو ما كابده أشد المكابدة، فقد اعتبر الديب أن هذه العاطفة السامية (الهوى) هي أهم أسباب ذلّه متناسياً معها أسباباً أخرى قد تكون أجدى لشعوره بالذل كإهمال قومه له وهو يعاني مرارة الأسى. ولعله من الواضح شعور الديب بالذل ولوم الهوى على ذلك؛ كونه لم يعش طفولته وشبابه حياة الترف، وإنها تربّى وعاش يجمل بين طياته روحاً وثّابة للقيادة حتى أصبح نموذجاً يُقتدى به.

وقد بالغ أبو فراس في تصوير الأثر الناشئ عن الحب مبالغة قربها إلى ذهن المتلقي بقوله (تكاد) في البيت:

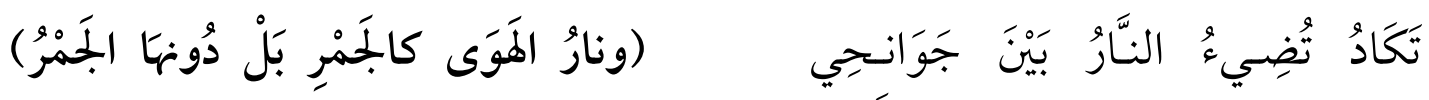

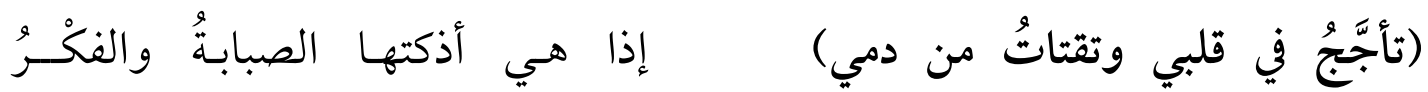
في حين لجأ الديب إلى التشبيه حينما وصف نار الهوى التي تكاد تضيء في صدر أبي فراس الذي فاقه الديب في وصفها فجعل الجمر دونها، وإذا ما عقدت المقارنة بين نار أبي فراس ونار الديب لؤجد أن الديب صرَّح بأن ناره تتأجج في قلبه وتتغذى من دمه في قوله:

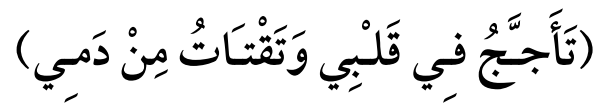

وهذا يعنى أن ناره أكثر إيلاماً من نار أبي فراس التي تكاد تضيء في صدره، ونار أبي فراس مجهولة الحرارة، ونار الديب أكثر حرارة من الجمر، فتصوير الذيب للنار أكثر تأثيراً من تصوير أبي فراس، فقد وسع الديب في معنى أبي فر اس وذلك بإضافة التشبيه الضمني حيث جعل من دمه وقوداً للنار المتأججة في قلبه. أما بيت أبي فراس:

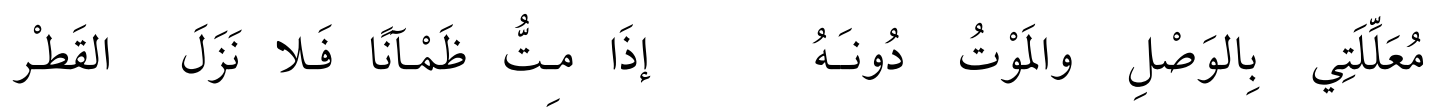


فقد عالج الديب فيه قضيتين: قضية في المصراع الأول، وقضية في المصراع الثاني، فقضيته الأولى: قضية الوصل التي جاءت في قول أبي فراس (معللتي بالوصل) فيضعه الديب في قضية شرطية، شرطاً وجواباً في قوله: "إذا صَحَّ مِنْكِ الوَصْلُ فَلْيَفْدِكِ العُمْرُ"؛ فأوضح بذلك ما يرمي إليه أبو فراس في قوله: (والموت دونه) وربط بين وقوع الو صل وذهاب الروح، لشدة تعلقه بمحبوبته.

أما القضية الثانية التي عالجها الديب فهي قضية الموت ظماً التي أوردها أبو فراس في بيته (إذا مت ظمآناً)،

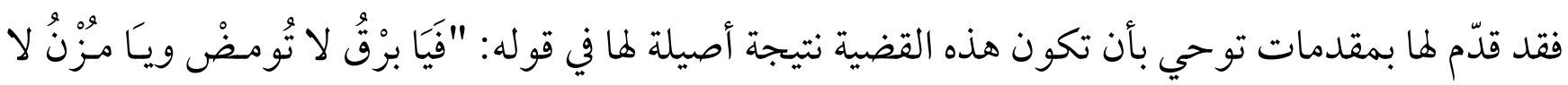
تَجُجْ "، وإن كان الخلاف واضحاً بين الشاعرين في المرمى ، فأبو فراس يرمي بالموت عطشاً إلى معنى ألاّيّم بينها الوصل، أما الذيب فقد حول لفظة (ظمآناً) من معناه المجازي إلى معناه الأصلي وهو قلة الماء من خلال ذلك النداء الذي يطلب فيه من البرق ألاّيومض ومن المزن ألاّ يجود، ومن المطر ألاّ يسقط ، على اعتبار أنه مصدر الماء، فصار البيت:

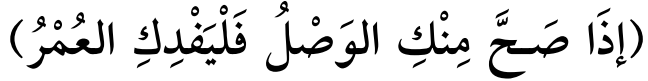

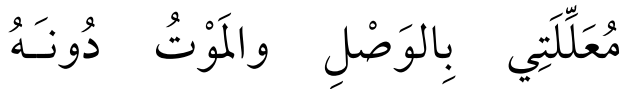

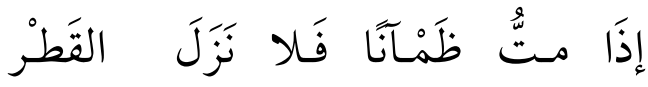
(فيَا بَرْقُ لا تُومِضْ ويَا مُزْنُ لا تَجْدُ)

أما في المقارنة بين موقف أبي فراس، ومحبوبته في حفظه للمودة وتضييعها لما، فيظهر لنا الديب متساهلاً واسع

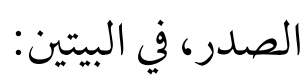

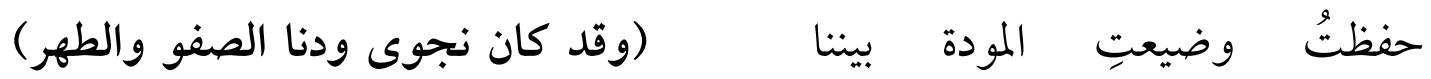
(فأجمل من عتب عليكِ تجمل) وأحسن من بعض الوفاء لك العذر فلا يجد ها عذراً في صدهـا وتمنعها؛ لأن علاقتهما مبنية على الصفو والطهر، وهي علاقة عذرية لا تعطي للمحبوبة الحق في كل هذا الهجر والصد، خلافا لأبي فراس الذي صرح بأن الاعتذار ها أفضل من أي شيء آخر، أو بلغة أخرى: إذا فُقد منك الوفاء، فاعتذري. وقد أفلح الديب في وصف الحديث بينها بالنجوى، أو المناجاة وهي الحديث سراً ويصوت مهموس يحمل حميمية وحنيناً، لا ينتهيان، خاصة وأنه أضاف هذه النجوى إلى الود ولا شيء غيره، وقد استفاد الديب من 
قدرته اللغوية في إضافة موسيقى خاصة جاءت من إيراده كلمتي (أجمل) و(تجمّل) وإن كان اختيار الشاعرين للفظين (أجمل)، (أحسن) اختياراً يظهر فروقاً طفيفة تتمثل في ما يحملانه من معنى، إلا أن الديب في اختياره كأنه يلوم أبا فراس ويرى في موقفه نوعاً من الضعف عبّر عنه بالعتب وكان أولى به أن يتجمل أي يصبر كما فعل هو. وينتقل أبو فراس من كلامه عن الهوى إلى الحكمة في قوله:

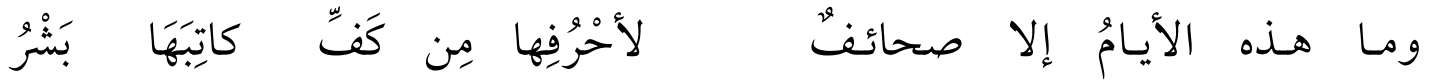
وقد جاراه الذيب في النسق نفسه فأكمل تفسير أسلوب القصر الوارد في المصراع الأول بحكمة أخرى تفيد تقلب الأيام وعدم ثباتها على حال ، ليصبح البيت بعد التشطير:

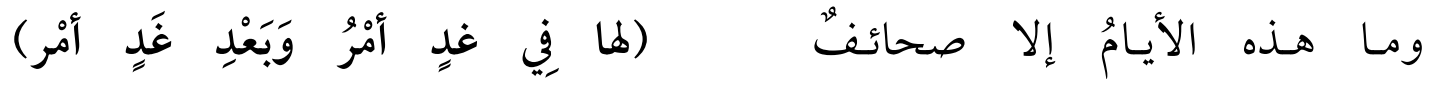

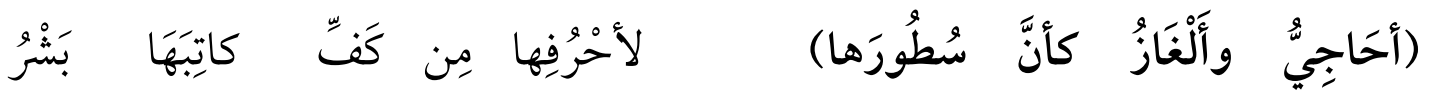
أما في البيت المشطر : - م

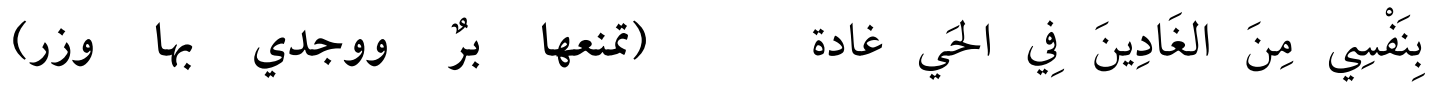

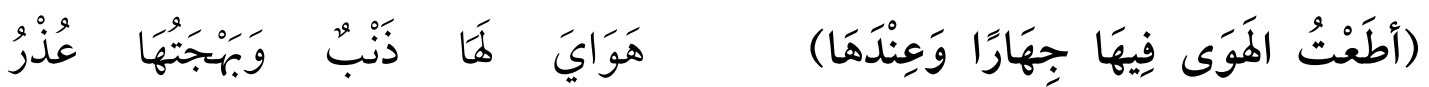
فقد كان الديب أقدر من أبي فراس على تصوير المعنى في البيت، فأبو فراس وإن وصفها بالغادة فإنه لم يزد على ذلك، واعتبر أن هو اه لها ذنب، في حين أن الذيب قد وصف تمنعها عن وصاله بأنه فعل جميل في رأيه (بُّو) بينما ترى هي حزنه وهيامه ووجده بها (وزراً) ارتكبه. وكما هو حاها عند أبي فراس الذي يرى أنها تُبرِّرُ هجرها له، ويذنب هو في هواه وتعلقه بها (هو اي ها ذنب) بينما (بهجتها عذر) في رأيها، وهذا نوع من العتاب يعانيه أبو فراس وصاحبه الديب على عادة الشعراء الذين يشكون الهجر ويدعون إلى الوصل. إلا أن الديب قد تفوق على أبي فراس الذي استهل قصيدته بتمرُّده على (الهوى) حيث قال على لسان مخاطبه في مستهل القصيدة: "أما للهوى نهي عليك ولا أمر".

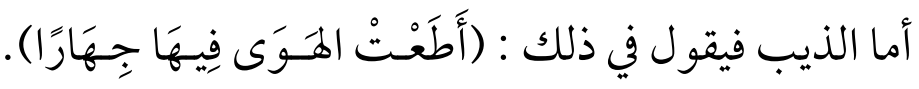




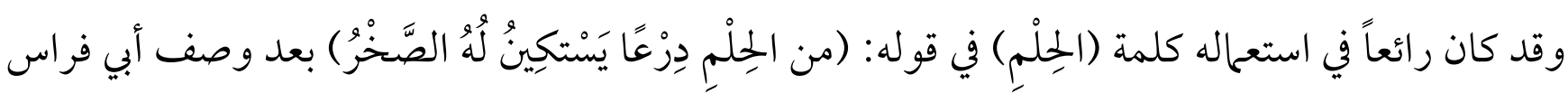

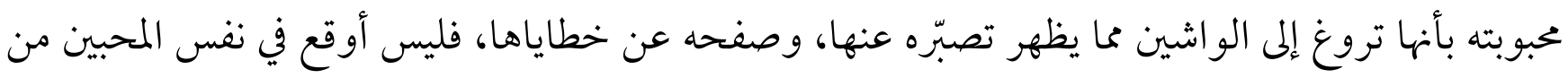

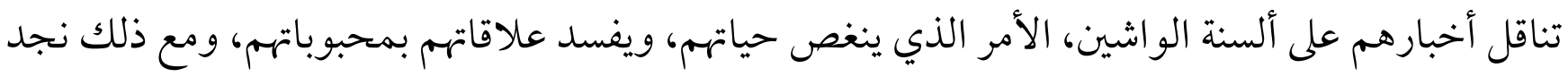
الديب يلبس درع الحلم والصفح ويبدو أن مفهوم (الحلم) الذي استعمله الديب أعمق من مفهوم (الوقر) الذي استعمله أبو فراس درعاً أيضاً يتدرع به حتى لا يسمع كلام الو اشين:

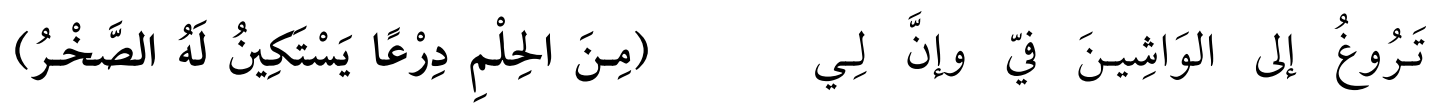

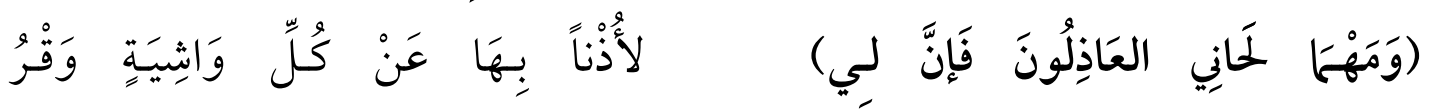
وقول الديب: (ومها لحاني العاذلون فإن لي) المتلوُّ بجملة خبرية مؤكدة بمؤكدين (إنَّ) و(اللام) في قوله: "فإنَّلي لأذنًا " ليدفع أي وهم يتبادر إلى ذهن المتلقي بأنه أصاخ السمع إلى العاذلين.

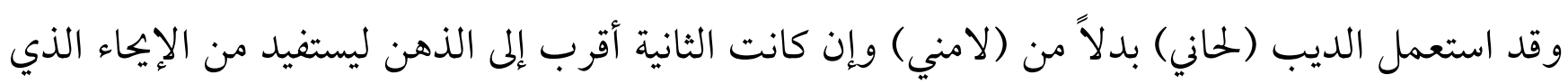
حمله حرف الحاء في (لحاني)، غير أن عجز البيت لا يو افق ما ذهب إليه الديب من مقدرة على مقارعة اللائمين؛ فقد جاء لفظ (واشية) غير ملائم لصدر البيت الذي ورد به (العاذلون) ولم يذكر (الواشين) ولعل ذلك يرجع إلى مرادفة الديب بين معنى لحاني وهو اللوم. ومعنى العذل في كلمة (العاذلون) الذي هو اللوم أيضا، أو أنه أراد تضمين (العاذلون) معنى (الواشين). وإذا ما لاحظ القارئ بيت أبي فراس:

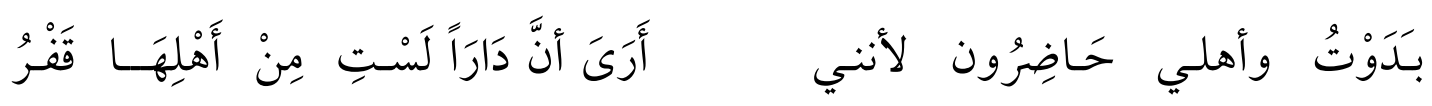
فلربا يظنّ أن البيت لا يحتاج في معناه بعد هذه الرؤية إلى أية إضافة، إلا أن الذيب استطاع أن يجمع بين أسرين

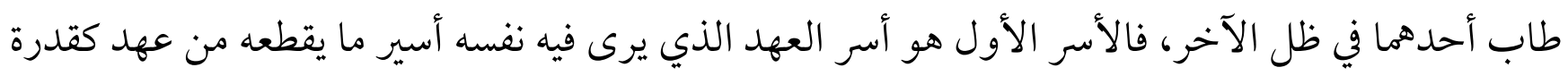
الأسر على حفظ الأسير، خاصة في كتم أمر الهوى، أما الأسر الثاني فهو السجن الذي يراه أهون من خيانة

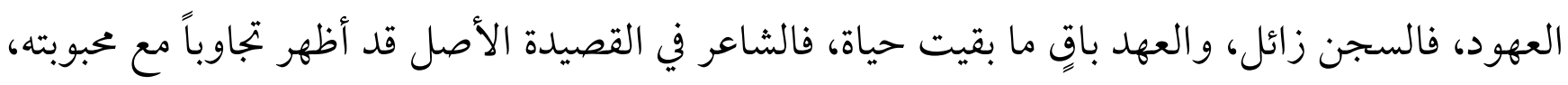


و أقام عليه الدليل، إلا أن الديب قد أظهر قدرته على أن يضيف عليها أسباباً أخرى، فيظهر أنه لم يهجرها نبذاً

$$
\text { وأصبح البيت بعد التشطير: ولاً تراً إلى غير عودة حيث قال: (وما عن قَلَ جافيتُ أهلي وإنها) }
$$

بَدَوْتُ و وأهلي حَاضِرُون ل لأنني

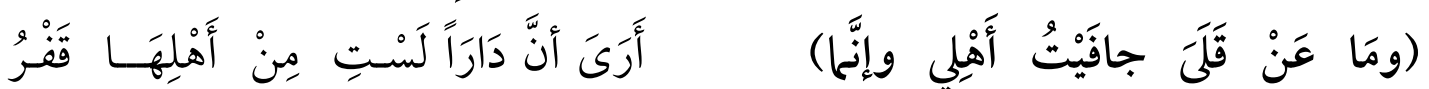

وقد استفاد الذيب من دراسته وحفظه للقر آن الكريم فاستعار منه موقفاً يناسب الموقف الذي هو فيه، حيث

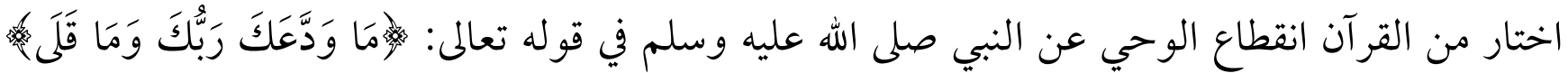
(الضحى: 3)، فهو لم يجافِ أهله بغضاً أو كرهاً، وإنما لأنه يرى أن داراً خلواً من محبوبته هي مفازة لا حياة فيها، ولم يكتف بأن جافى أهله، بل حاربهم، وهي نتيجة منطقية، فليس بعد الجفاء إلا الحرب. ويظهر التوافت بين الذيب مع أبي فراس في الاعتداد بالذات، فقد أسبخ الديب على أهله صفات اختار لها صيغاً صرفية تناسب فخره بهم فجاءت (مناجيب) على صيغة منتهى الجموع لتوحي بكثرتهم وقوتهم، إضافة إلى كرم أحسابهم ومحمود فعالهم وأقو الهم. وقد أضاف هذه الصيغة إلى المجد وقارنه بالأنجم الزهر في قوله:

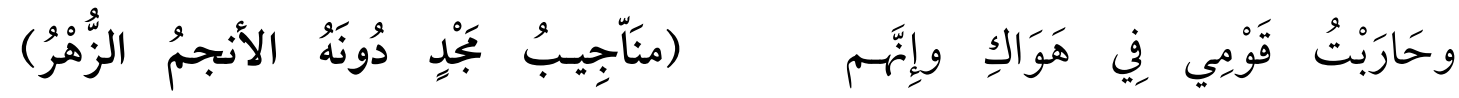

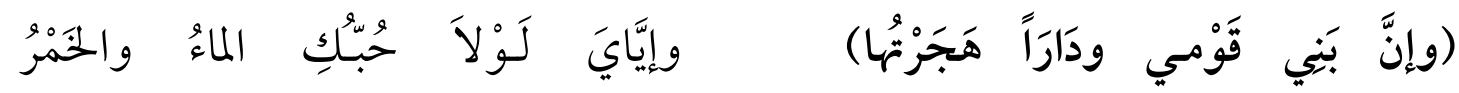

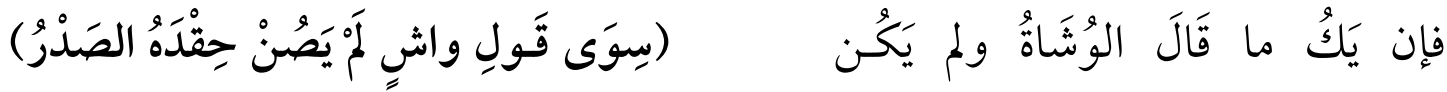

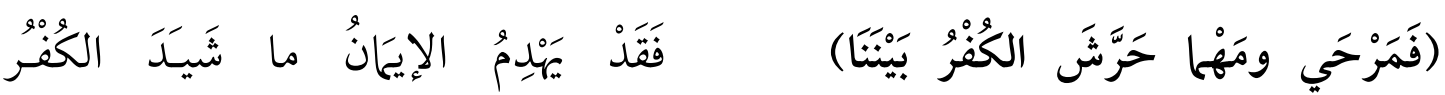

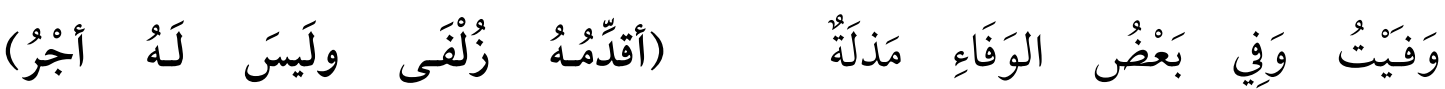

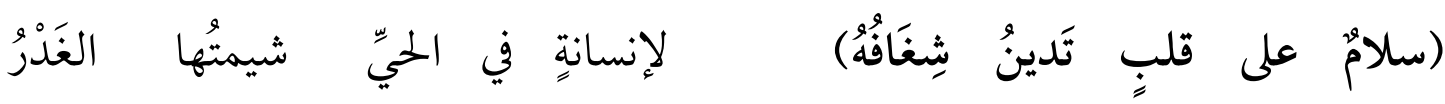

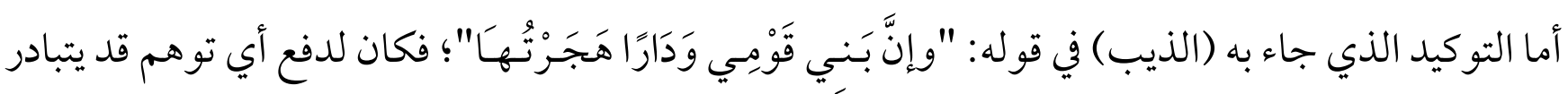
إلى الذهن في معاداة الشاعر لقومه، وليؤكد حقيقة أن ما دفعه إلى هذا الوضع هو الحب ولا شيء سواه. ويظهر 
(الذيب) مرة أخرى اعتداده بشخصيته في تعريفه وتوضيحه لأقو ال الوشاة بأنها أحقاد ينفثها حاملوها من

$$
\begin{aligned}
& \text { صدورهم، ويظهرونها على عجز منهم في صونها داخل الصدر في قوله: }
\end{aligned}
$$

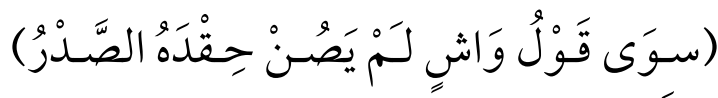

ويشبه صنع الوشاة الحاقدين - في البيت التالي بالكفار الذين أظهرتهم أحقادهم على حقيقتهم ، وإن لم يكن كفر معتقد وإنها هو كفر بالقيم الإنسانية النبيلة وعلى رأسها الحب:

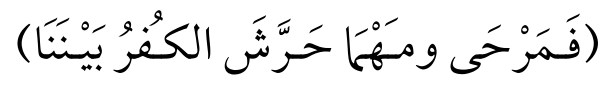

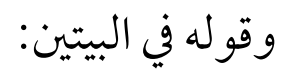

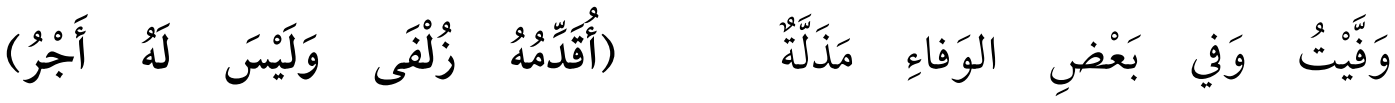

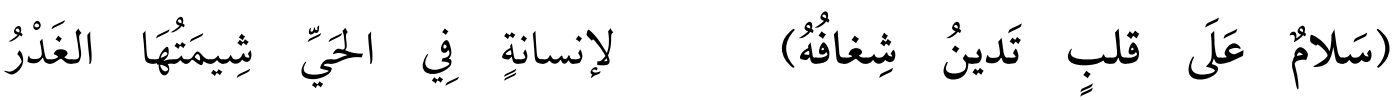

فالديب هنا يقدم وفاءً متقرباً به لحبيته و لا ينتظر منها أجراً، ويكيي قلباً تدين شغافه لإنسانة من شيمها الغدر. وهي تضحية نادرة يقدمها عاشق لمن لا وفاء له؛ لأننا نرى في الو اقع أنه لا وفاء لمن اتصف بالغدر، وهو الأمر الذي جعل أبا فراس يراه (مذلة) ولم يكتفِ الذيب بذكر (القلب) بل زاد عليه (شغافه) ليظهر مدى تمكن حبها من نفسه، وهنا تظهر قدرته الفائقة في الغزل التي تضاهي مقدرة أبي فراس إن لم تزد عليها. ويظهر اختيار الذيب لمو اطن الجمال في المرأة اختياراً صائباً دقيقاً فوق صاحبه أبي فراس الذي يقول:

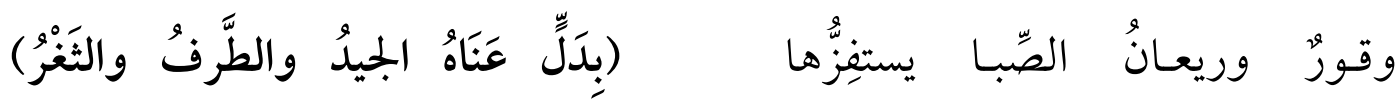

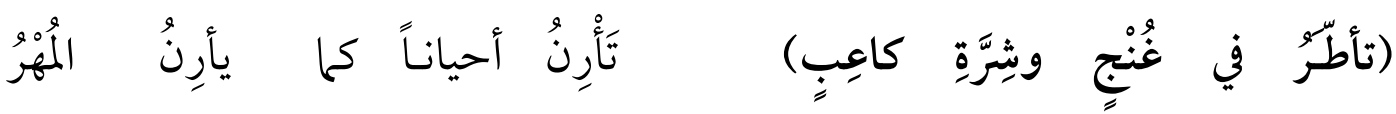
فما اهتم به الحمداني في مظهرها هو رشاقتها وخفة حركتها التي جاءت في تشبيهه لها بالمهر الكثير الحركة في قوله:

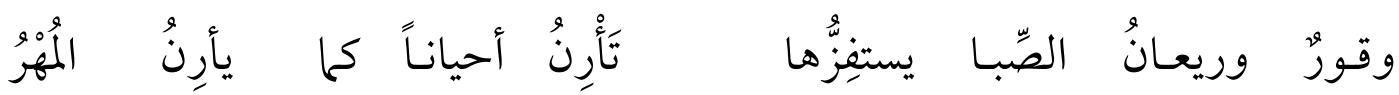
وقد يكون هذا الوصف ناجماً عن حياة الفروسية التي عاشها هذا الشاعر، أما الذيب فكان أقدر على تقدير مو اطن الجمال في المرأة وتصويرها، حيث اختار صفتي الدلال والتيه من خلال جمال جيدها وعينها وثغرها؛ 


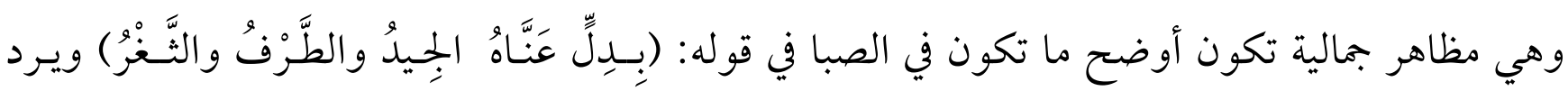

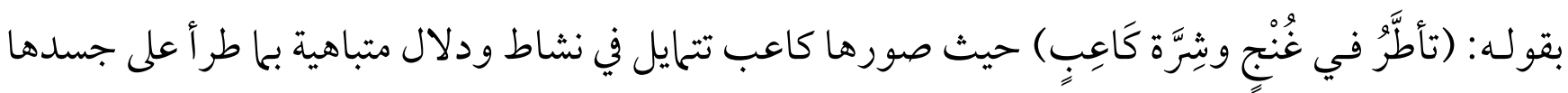

$$
\begin{aligned}
& \text { من تحولات أنثوية. } \\
& \text { ويخرج (أبو فراس) عن الغزل مرة أخرى إلى الفخر في قوله: }
\end{aligned}
$$

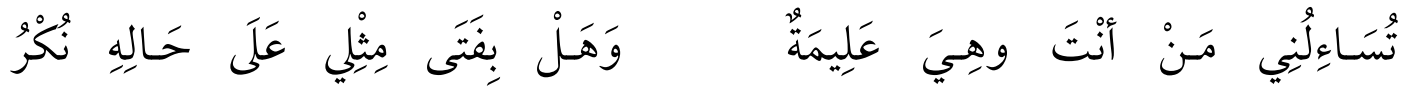

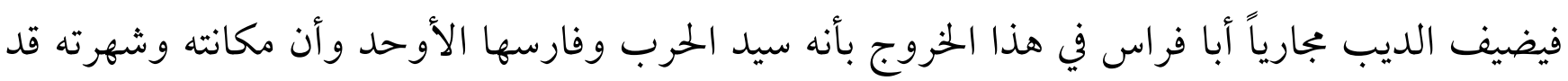

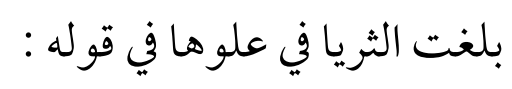

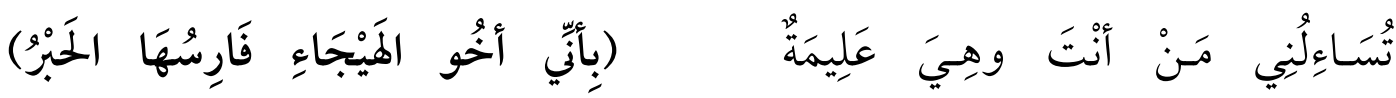

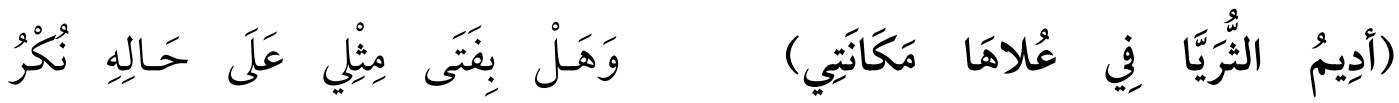

غير أن أبا فراس جعل من نفسه إنساناً نكرة أمام محبوبته وفي ذلك تذلل كبير لا يتوقع أن يكون من شاعر في في في موقع الفخر والحماسة، في الوقت الذي جعل فيه الذيب نفسه علماً في الحرب والسلم، فقد عرَّف نفسه بأنه فارس للحرب وذو مقام لا يبارى، ولولا بلاغة الديب التي طغت في البيت المقصود لكان أبو فراس فيه متواضعاً كثيراً.

وتظهر قوة الديب في الغزل مرة أخرى في تصويره لمظاهر الجمال الصريحة في المرأة وتقسيمه لعين المرأة من

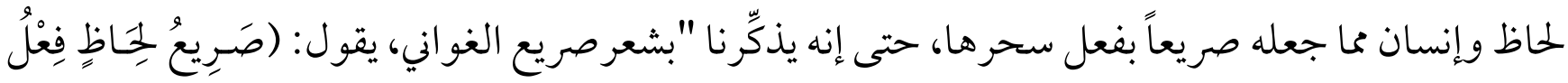

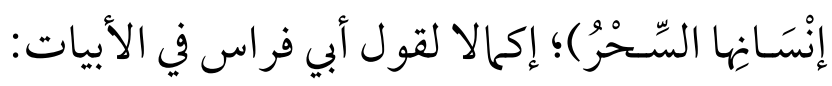

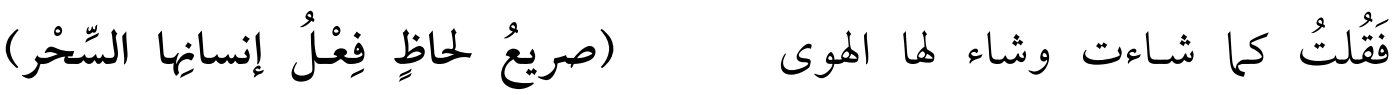

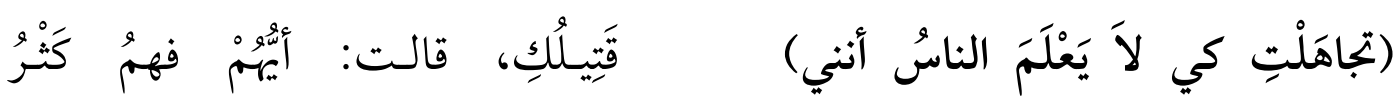
ومقابل كل تلك الصفات التي وصف بها (أبو فراس) محبوبته من غدر وتنكر، يهد الذيب عذراً منجياً ها؛

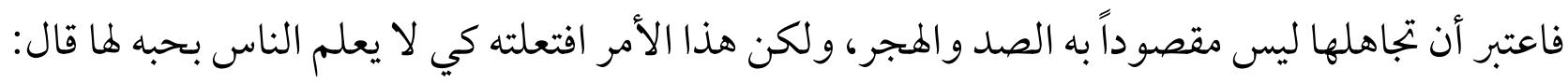

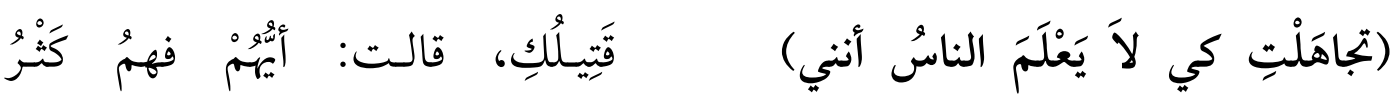


ويختلف الذيب وأبو فراس في نتيجة الفكرة في المحاورة مع الحبيبة والعاشقة.

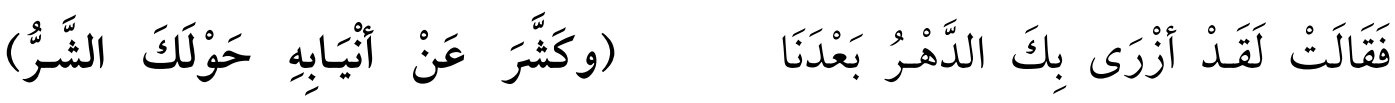

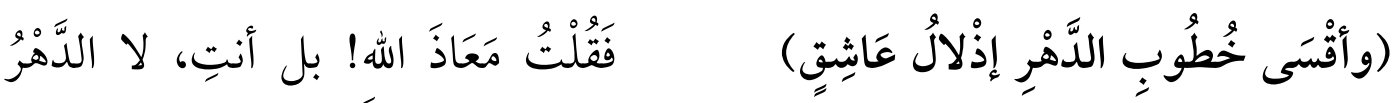
فأبو فراس حين أخبرته محبوبته بأن الدهر قد جعله في حالة مزرية، كان ردَّه أنها هي من أزرى به وليس

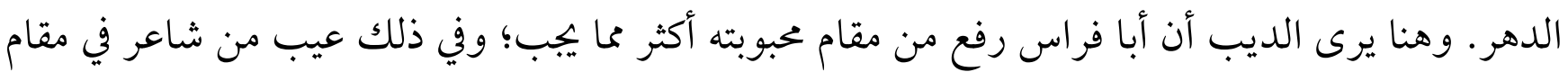
الفخر مثل أبي فراس. خلافاً للديب الذي جعل من هذه المعشوقة تننكر لحبيبها وتكشر له عن أنيابها ، ويمثّل الخطوب التي تذل العاشق أوفي ذلك تقليل من شأنها مقارنة بقول أبي فراس الذي جعلها أكثر إزراءً من الدهر الدهر

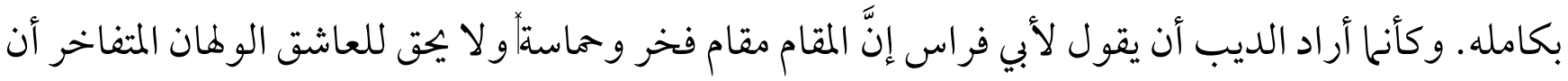
يتذلل ويتواضع إلى هذا الحد، بل عليه أن يذكر مواضع فخره وعزته، وعلو شأنه، وقوة شكيمته، ورفعة إنها

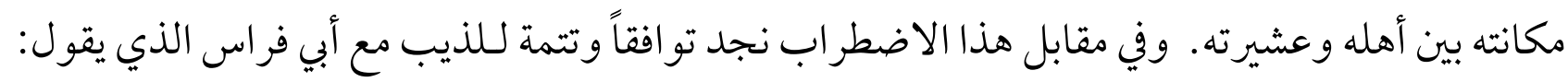

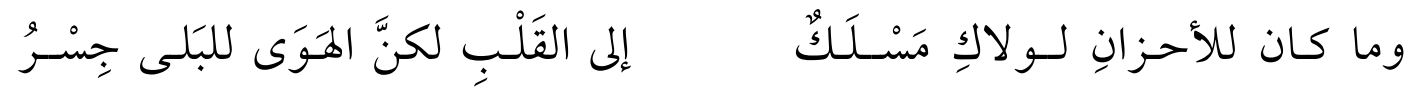
فها أجمله أبو فراس في بيته السابق؛ فصَّله الديب في قوله:

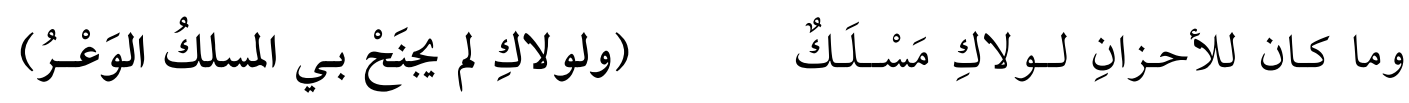

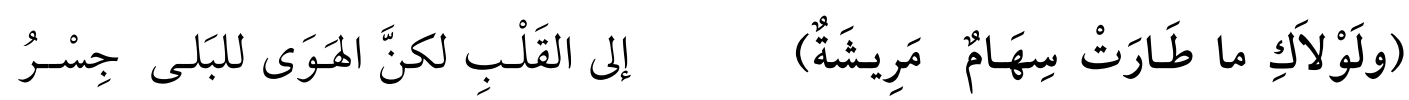

ويفضَّل شاعرنا الديب في أغلب أوصافه استعال المضارع للدلالة على الاستمرار فيعقد به مقارنة بين هلاك النفس وبين الجد والهزل في قول أبي فراس، وذبول الزهر بين الروض والباقة في قوله هو، أي الذيب كما هو ملاحظ:

(ويَذْبُلُ بَيْنَ الرَّوْضِ والبَاقَّة الزَّهرُْو)

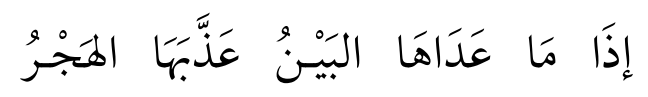

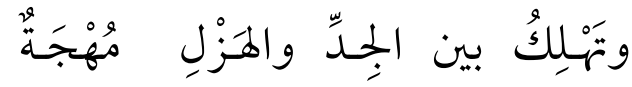

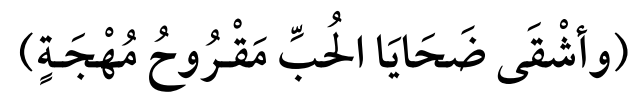


فأبو فراس يرى الجد طريق الحياة، والهزل طريق الموت والهلاك، وقد أخذ ذلك من طبيعته العسكرية، فأية غفلة تَعني أن العدو تمكّن منه تماماً كما هي حال الزهر: في روضته، حياة، وفي باقته موت وهلاك، وباستعحال الذيب اسم التفضيل (أشقى) وإضافته إلى ضحايا الحب، يظهر حجم المعاناة التي يعيشها، والتي أخبر عنها بـ(القروح) التي تصور شدة الألم خاصة إذا كان القرح معنوياً يطال المهجة وليس مادياً يطال الجسد الذي سرعان ما تبر أ جر احه وتلتئم.

\section{الخاتثـــة}

ناقش البحث نماذج من التشطير ولمَّح إلى مواضع البيان في تلك التجربة الثرية، لمحاولة إثبات ما يأتي: 1 - الصورة عند الديب تقليدية منتزعة من البيئة، ولعل ما ساعده في ذلك الشبه الكبير بين بيئته وبيئة

$$
\text { الحمداني، فالمسمَّيات في المجتمعين تقريباً عربية أصيلة. }
$$

2- إنّ قيد التشطير وتحكُّم النص الأصل في طريقة الصياغة، جعل من الشاعر المشطرّ أسيراً للصورة، مثلما كان أسيراً للوزن والقافية. ومع كل هذه القيود فإن أبيات التشطير لا تقل قوة وجزالة ورصانة عن أبيات القصيدة الأصل.

3 - لم تخذل المشطرّ ثقافته، أو تَّنْهُه معرفته؛ فقد استطاع أن يقف على كل الأفكار والمعاني والمرامي التي توخَّاها الشاعر الأصل في القصيدة المُشطََّرِة: 4 - اعتداد الشاعر علي الديب، بمقدرته اللغوية والشعريـة فهو يرى أنه لا يقل قيمة فنيـة، أو أدبية، أو مكانة اجتهاعية عن (أبي فراس)، فتشطيره لهذه القصيدة دليل على مقدرة المشطرّ، وطول نَفَسِهِ في الشعر نظلًا

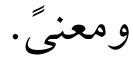
5- تشابه ظروف الحياة بين الشاعرين؛ فـ(أبو فراس) شاعرُ أمير أسره الروم، فصاغ أرقّ شعرِه وأجملَه في سجونهم، وعلي الديب كذلك فقد تقلّد المناصب العليـا في حكومـة الدولة الليبية فجرَ نشأتها ثم زُجّ به في السجن، وعانى ما عاناه أبو فراس، ونظمم تشطيرته بين قضبان السجن. 
6- استيعاب (علي الديب) لمرامي (أبي فراس) في قصيدته التي عايشها، فتمكَّن من امتلاك ناصية النص

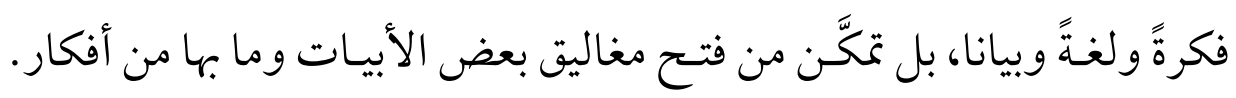

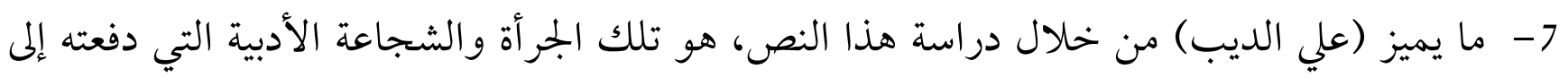

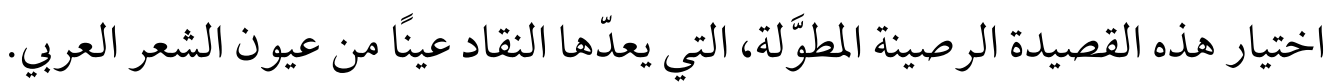
8- يتمتع (علي الديب) بشاعرية تصقلها ثقافته وسعة إطلاعه، وتهذبها الحكم والأمثال التي في يخزونه الفكري.لذلك استطاع الديب أن يتفاعل مع الأحداث واستخراج المعاني، والاستشراف منها على أفق

في الحتام فإننا أمام تجربة أدبية شعرية تستحق التأمل والاهتحام بمُجيديها في سبيل توطيد الأواصر بين الذوق

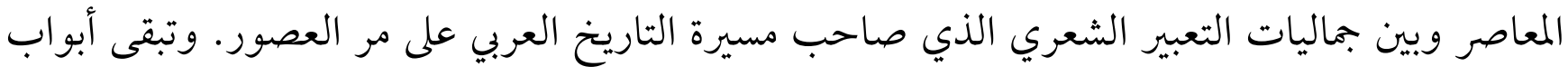

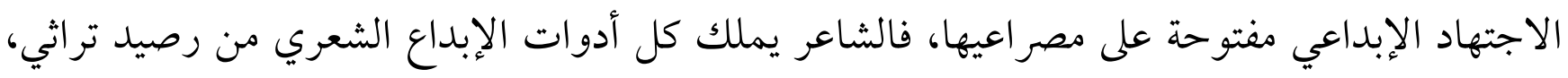
ولغة وقدرة على نقل التراث في ثوب عصري متجدد، لذا بات من الضروري الاهتحام بالأدب العربي شعراً

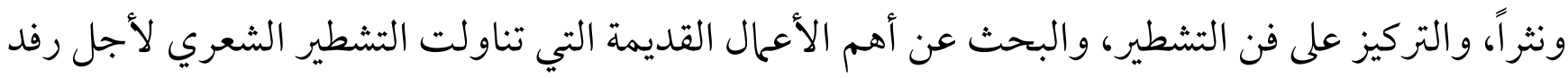
المكتبة الجامعية بمثل هذا النوع الشعري الفريد، لتمد القاريء العربي بها يهفظ له هويته، ويهفظ للقصيدة العربية أصالتها وجودتها وإبداعها في كل زمان.

المصادر والمراجع: المبر

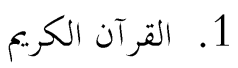
2. ابن الأثير، أبو الفتح، المثل السائر في أدب الكاتب والشاعر، تتقيق: أحمد الحوفي، وبدوي طبانه، لا ط، دار النهضة، 1972،

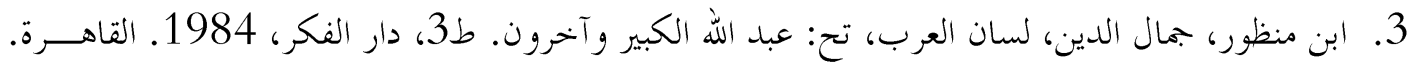

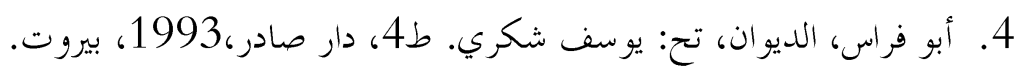


5. خلوصي، صفاء الدين، فن التقطيع الشعري، ط2، مكتبة المثنى، 1977. بغداد.

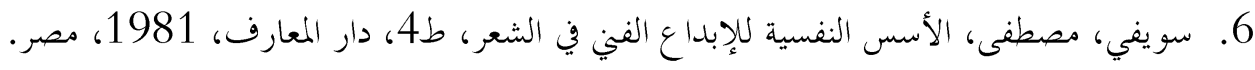

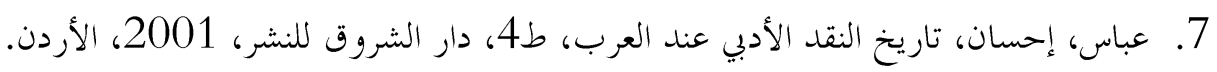
8. محمد محمود قاسم نوفل، تاريخ المعارضات في الشعر العربي. مؤسسة الرسالة الأولى، 1983.

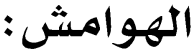

(1) عباس، إحسان، تاريخ النقد الأدبي عند العرب، الأردن:دار الشروق للنشرص65، 2001 (2)

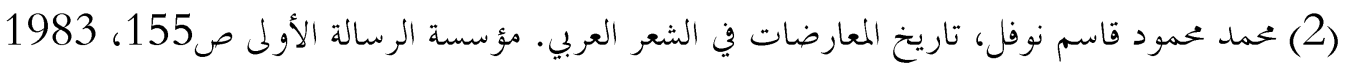

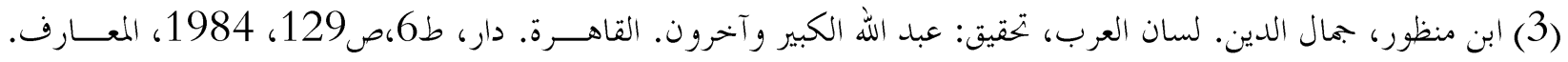

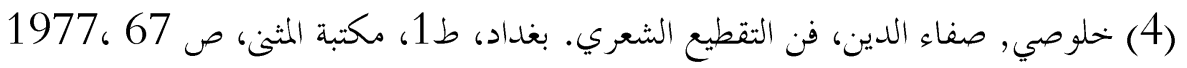

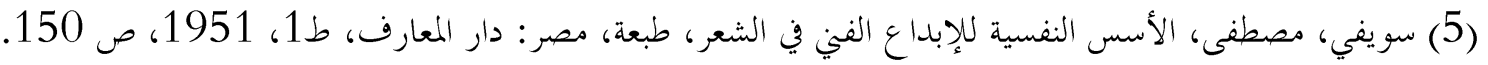

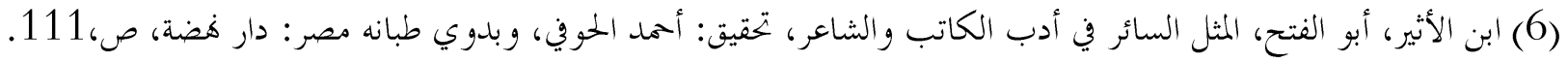

